九州大学学術情報リポジトリ

Kyushu University Institutional Repository

\title{
Three New Species of the Subgenus Evylaeus of the Genus Lasioglossum from Eastern Asia (Hymenoptera, Halictidae)
}

Murao, Ryuki

Entomological Laboratory, Graduate School of Bioresource and Bioenvironmental Sciences, Kyushu University, Fukuoka

Ebmer, Andreas Werner

Kirchenstraße 9, A-4048, Puchenau, Austria

Tadauchi, Osamu

Entomological Laboratory, Faculty of Agriculture, Kyushu University, Fukuoka

https://doi.org/10.5109/2860

出版情報: ESAKIA. 46, pp.35-51，2006-06-30. Entomological Laboratory, Faculty of Agriculture， Kyushu University

バージョン：

権利関係 : 


\title{
Three New Species of the Subgenus Evylaeus of the Genus Lasioglossum from Eastern Asia (Hymenoptera, Halictidae)
}

\author{
Ryuki Murao $^{1)}$, Andreas Werner Ebmer ${ }^{2)}$, and Osamu Tadauchi ${ }^{3)}$ \\ 1) Entomological Laboratory, Graduate School of Bioresource and Bioenvironmen- \\ tal Sciences, Kyushu University, Fukuoka, 812-8581 Japan \\ 2) Kirchenstraße 9, A-4048, Puchenau, Austria \\ 3) Entomological Laboratory, Faculty of Agriculture, Kyushu University, Fukuoka, \\ 812-8581 Japan
}

\begin{abstract}
Three new species belonging to the subgenus Evylaeus of the genus Lasioglossum (Halictinae, Halictini) are described from Eastern Asia: L. caliginosum sp. n. and L. miyabei sp. n. from Japan and Far East Russia, and L. yamanei sp. n. from Japan. The three new species are placed into the following species-groups based on Ebmer's classification: L. caliginosum into the fulvicorne-fratellum species-group, and L. miyabei and L. yamanei into the atroglaucum species-group. Photographs, illustrations and SEM photographs of important characters are provided for each species. In addition, diagnosis, distribution map, flight records and floral associations for each species are also given.
\end{abstract}

Key words: Hymenoptera, Halictidae, Halictinae, Halictini, Lasioglossum, Evylaeus, fulvicornefratellum species-group, atroglaucum species-group, new species.

\section{Introductoion}

The late Prof. Sakagami attached a temporary specific number to each undescribed or unknown species in an effort to catalog the Japanese halictine bees until accurate scientific names could be established (Sakagami, 1979, etc.). These specific numbers have been used in subsequent reports of the distribution of Japanese halictine bees by many researchers. Most of the specific numbers have been replaced with accurate scientific names. However, the taxonomic status of the three species, Lasioglossum (Evylaeus) sp. 2B, L. (E.) sp.2 or $L$. (Dialictus) sp. 2, and $L$. (E.) sp. 3 or $L$. (D.) sp. 3 has not been resolved. In Japan, $L$. sp. $2 \mathrm{~B}$ and $L$. sp. 2 have been recorded from Hokkaido, Honshu, and Shikoku, while L. sp. 3 has been recorded from Honshu, Shikoku, and Kyushu (Goubara et al., 2002). In addition, L. sp. 2B has been recorded from Far East Russia (Ebmer, 1995).

Through our on-going study of Palaearctic Evylaeus, we recognized these three species as undescribed species. In this paper, we therefore describe $L$. sp. 2B as $L$. caliginosum, L. sp. 2 as L. miyabei, and L. sp. 3 as $L$. yamanei. We also discuss the taxonomic position of the three new species based on Ebmer's classification.

\section{Materials and Methods}

The specimens examined in this study were borrowed from the following institutions and personal collection, which are referred to in the text by the following abbreviations: $\mathbf{S C M H}=$ the late Dr. Shôichi F. Sakagami's Collection, Museum of Nature and Human Activities, Hyogo Pref., Japan; ECPA= P. Andreas Werner Ebmer's Collection, Puchenau, Austria; ELKU= Entomological Laboratory, Faculty of Agriculture, Kyushu University, Fukuoka Pref., Japan; MCMG= Mr. Michael Quest's Collection, Münster University, Münster, Germany. Other specimens without abbreviation belong to private collection (R. Murao), which is temporarily kept at the Entomological Laboratory, Kyushu University, Fukuoka Pref., Japan.

The morphological terminology in the description follows Eickwort (1969), McGinley (1986), Sakagami and Tadauchi (1995), and Michener (2000). The terms and their abbreviations used are as follows: $\mathbf{F} n=n$th flagellar segment; $\mathbf{T} \boldsymbol{n}, \mathbf{S} \boldsymbol{n}=n$th metasomal tergum and sternum; $\mathbf{P P}=$ Punctures; $\mathbf{I S}=$ Interspace of punctures.

E-mail: rm1978@agr.kyushu-u.ac.jp 
Table 1. Major differences among L. caliginosum, L. vulsum and L. baleicum.

\begin{tabular}{|c|c|c|c|}
\hline Feature & caliginosum & vulsum & baleicum \\
\hline Female vertex & See Fig. 4. A & See Fig. 4. B & See Fig. 4. C \\
\hline $\begin{array}{l}\text { Basal elevation and } \\
\text { distal process of female } \\
\text { labrum }\end{array}$ & See Fig. 2. A & See Fig. 3. A & See Fig. 3. B \\
\hline $\begin{array}{l}\text { Color of } \\
\text { male clypeus }\end{array}$ & $\begin{array}{l}\text { black or the lower } \\
1 / 3 \text { dark yellow }\end{array}$ & lower half yellow & black \\
\hline $\begin{array}{l}\text { Color of } \\
\text { male tibia }\end{array}$ & black & $\begin{array}{c}\text { above and below } \\
\text { yellow }\end{array}$ & black \\
\hline $\begin{array}{l}\text { Bottom of gonobasal } \\
\text { ventral arm (Fig. 6. J-L) }\end{array}$ & nearly flat & nearly flat & $\begin{array}{l}\text { medially } \\
\text { depressed }\end{array}$ \\
\hline $\begin{array}{l}\text { Gonostylus in ventral } \\
\text { view (Fig. 6. A,C,E) }\end{array}$ & ovate & apically truncate & round \\
\hline $\begin{array}{l}\text { Ventral retrorse lobe } \\
\text { (Fig. 6. G-I) }\end{array}$ & broad & slender & slender \\
\hline
\end{tabular}

\section{Lasioglossum (Evylaeus) caliginosum sp. $\mathbf{n}$.} (Figs. 1. A-H; 2. A, B; 4. A; 5. A-C; 6. A, B, G, J; 13. A)

\section{Diagnosis}

Female: the face with sparse hairs; the supraclypeal area and clypeus with sparse PP; the mesoscutum with dense PP, IS reticulate; T3-4 with fine and scattered PP, IS transversely striate. Male: the clypeus black or the lower $1 / 3$ of clypeus dark yellow; the flagellum beneath blackish brown; the mesoscutum similar to female; the gonostylus ovate in dorsal and ventral views (Fig. 6. A, B); the ventral retrorse lobe broad, with short hairs (Fig. 6. G).

This species is closely similar to Lasioglossum vulsum (Vachal, 1903) and L. baleicum (Cockerell, 1937) in having the following morphological characters: similar shape and sculpture of the head in female and male; the mesoscutum with dense granular PP over the surface, IS with distinct reticulation in female and male; the mesepisternum with coarse rugulae in female; the sculpture of propodeum and metasomal terga in female and male. Table 1 indicates the differences among these three species.

\section{Description}

Female. Body length 6.1-7.0 mm, Wing length 5.6$6.2 \mathrm{~mm}(\mathrm{n}=5)$.

Color. Body black except as follows: mandible with apical half reddish brown; flagellum beneath blackish brown; tegula brownish transparent; wings nearly transparent; veins yellowish brown; pterostigma brown; legs blackish brown; tibial spur yellow; posterior margins of metasomal terga broadly yellowish brown transparent.

Pilosity. Body hairs pale yellowish brown to whitish. Hairs on head finely branched, sparse. Hairs on mesosoma finely branched except as follows: lateral lobe of pronotum and medial area of metanotum with dense tomentum; hind femur with plumose hairs, forming scopa. Anterior and lateral hairs on $\mathrm{T}_{1}$ finely branched, sparse. Hairs on T2-4 simple and short, and mixed with a few fine branched hairs. Hairs on $T_{5}$ finely branched, moderately dense. Basal hair bands on T2-4 whitish and tomentum. Hairs on metasomal sterna finely branched and moderately dense, and mixed with a few simple hairs.

Structure. Head width slightly longer than head length; head length/width ratio 0.91-0.99 $(n=10)$. Vertex behind ocelli with transverse ridges. Distance between lateral ocelli as long as distance between lateral ocellus and compound eye. Frons dull and nearly flat, with 
cancellate PP (20-30 $\mu \varnothing)$. Paraocular area weakly shiny, with cancellate PP (20-40 $\mu \varnothing)$. Supraclypeal area slightly convex in lateral view, weakly shiny, with sparse granular PP (25-28 $\mu \varnothing)$; IS very weakly reticulate. Clypeal length about 1.2 times the distance between lower rim of antennal socket and upper margin of clypeus. Clypeus nearly flat, weakly shiny, with sparse granular PP (20-30 $\mu \varnothing)$; IS weakly reticulate above, scarcely reticulate below. Basal area of labrum about 2 times as wide as long, apically slightly depressed in frontal view; basal elevation well developed, narrow apically; lateral projection of distal process absent; keel of distal process moderately broad, apically obtuse in frontal view; labral fimbria all acutely pointed at apex. Mandible bidentate. Hypostomal carina moderately developed; anterior angle of hypostomal carina obtuse. Postgena reticulate. Genal area with oblique ridges. Scape length 0.8-0.92 $\mathrm{mm}(\mathrm{n}=$ 5), F1 length as long as F2.

Pronotum with dorsolateral angle obtuse; lateral sulcus distinct. Mesoscutum weakly shiny, with dense granular PP (15-25 $\mu \varnothing)$ over the surface; IS distinctly reticulate. Mesoscutellum nearly flat, its sculpture similar to mesoscutum. Metanotum dull, with weak rugulae. Mesepisternum weakly shiny, with coarse rugulae. Metepisternum with transverse ridges in upper half, with weak rugulae in lower half. Basitibial plate of hind legs ovate, pointed apically. Inner hind tibial spur with 2-6 teeth $(n=128)$. The length of propodeal dorsum as long as mesoscutellum, and about 2 times those of metanotum; propodeal dorsum gently inclined; propodeum dorsally with distinct ridges over the surface, laterally with longitudinal ridges attaining to lateral slope, medially

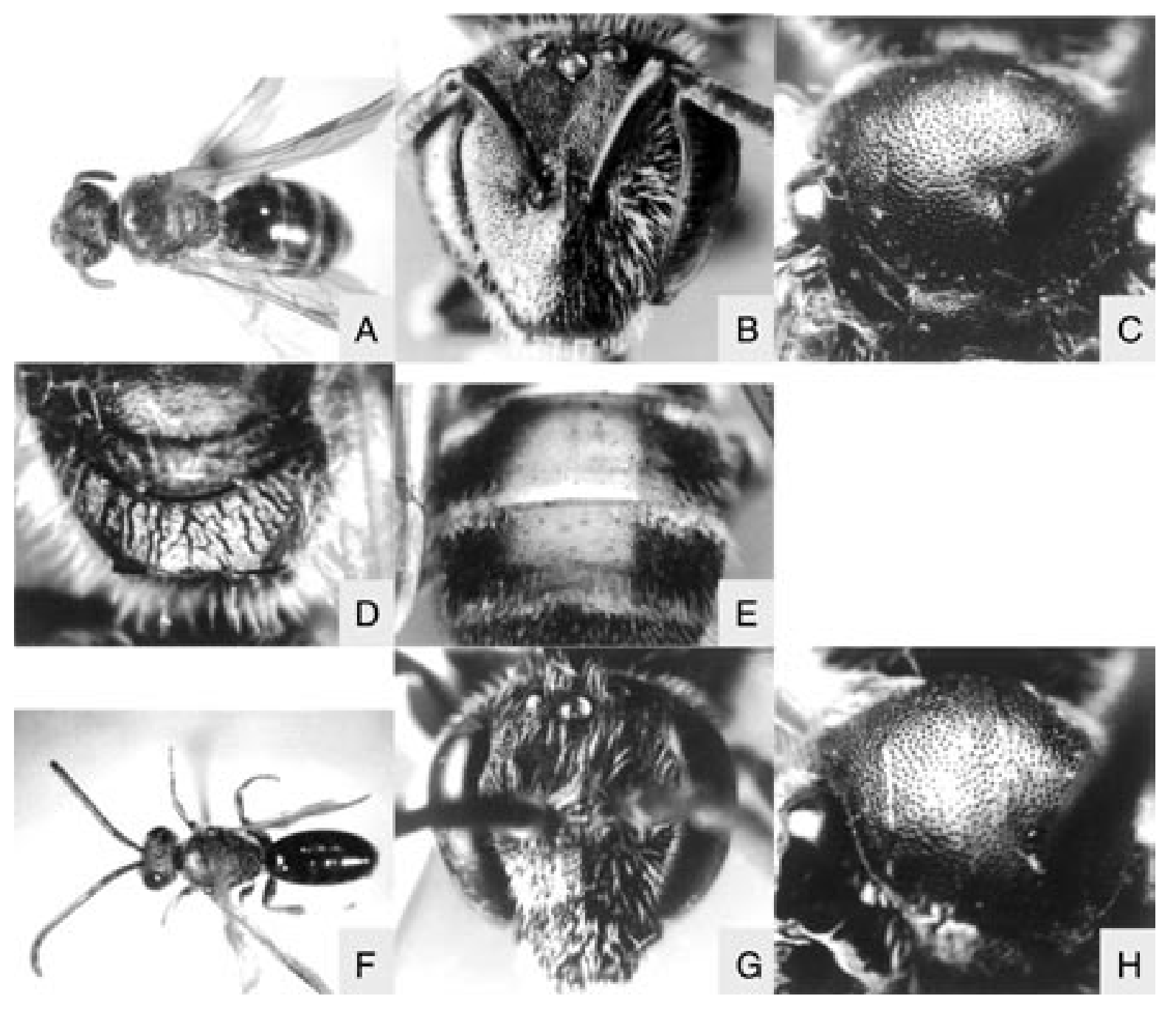

Fig. 1. A-H. Lasioglossum (Evylaeus) caliginosum sp. n. Female, holotype: A, general habitus; $\mathrm{B}$, head in frontal view; $\mathrm{C}$, mesoscutum; $\mathrm{D}$, propodeal dorsum; $\mathrm{E}$, metasomal tergum third and fourth. Male, paratype: F, general habitus; G, head in frontal view; H, mesoscutum. 


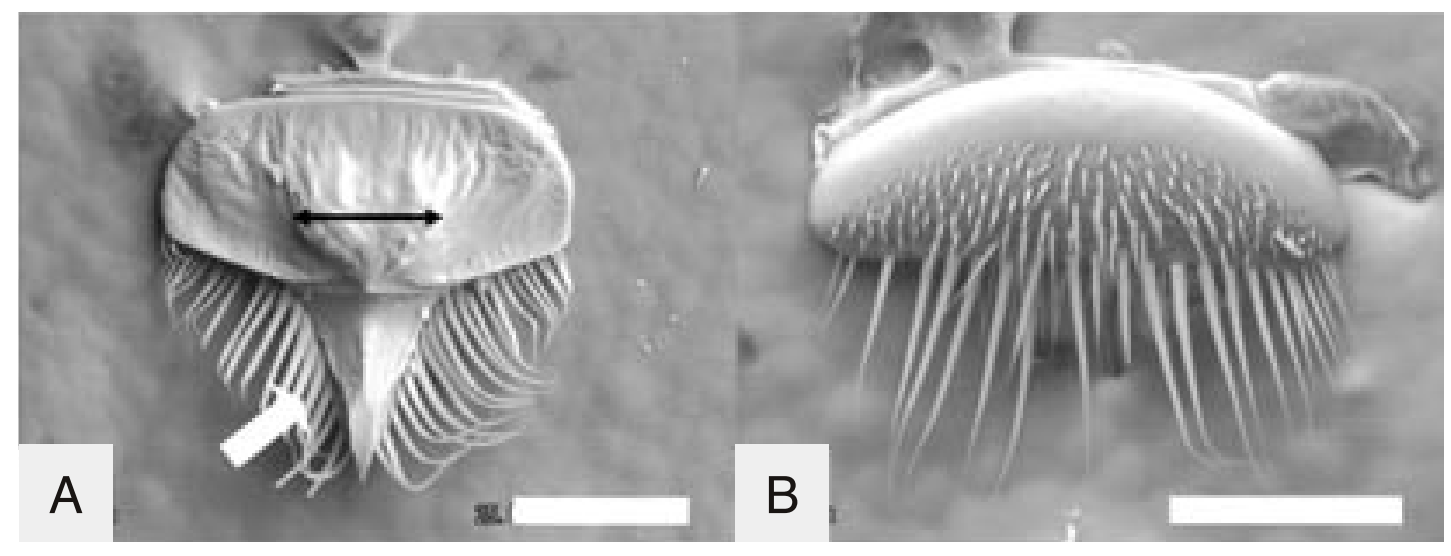

Fig. 2. A-B. Labrum, paratype. Lasioglossum (Evylaeus) caliginosum sp. n. A: female. B: male. Scale: $0.2 \mathrm{~mm}$.

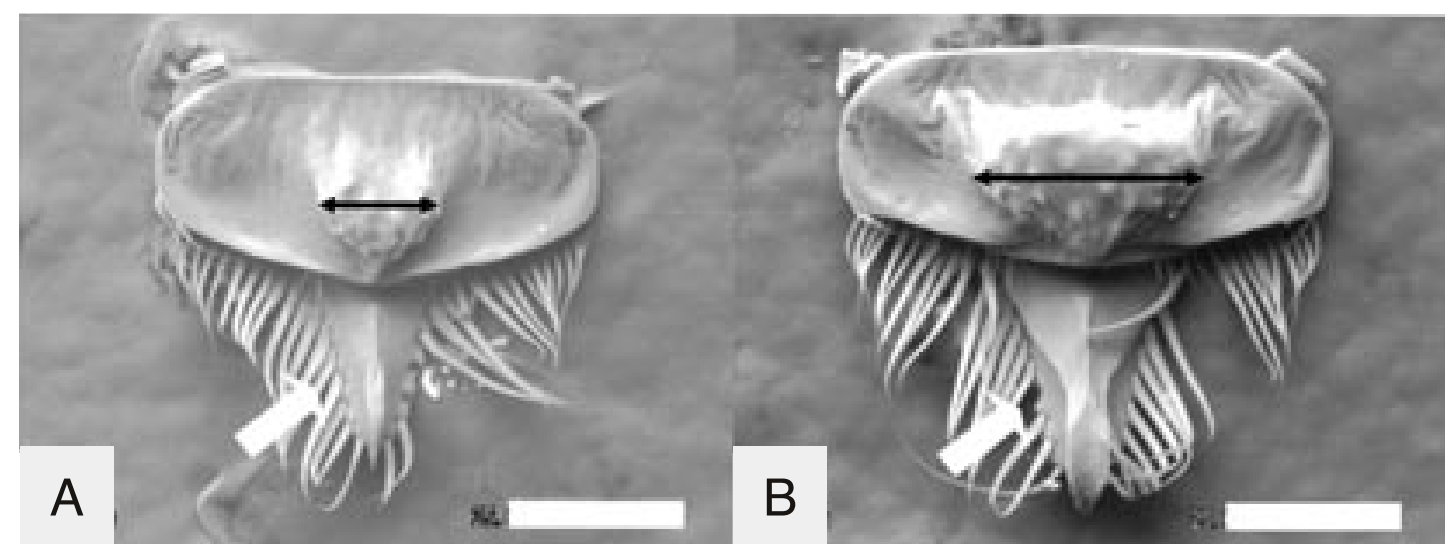

Fig. 3. A-B. Female labrum. A: Lasioglossum (Evylaeus) vulsum (Vachal). B: Lasioglossum (Evylaeus) baleicum (Cockerell). Scale: $0.2 \mathrm{~mm}$.

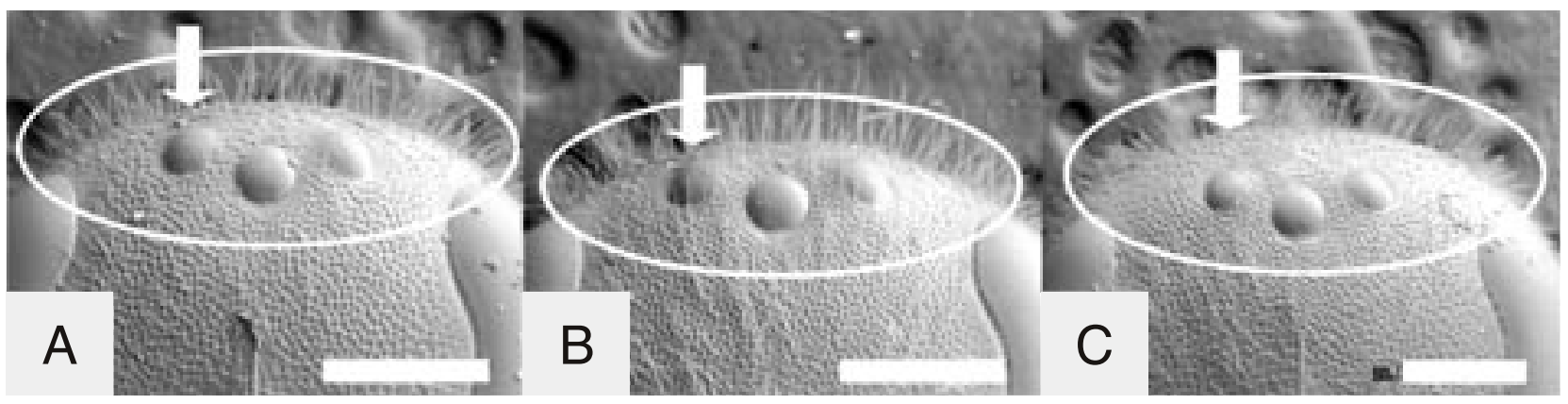

Fig. 4. A-C. Female vertex in frontal view. A: Lasioglossum (Evylaeus) caliginosum sp. n., paratype. B: Lasioglossum (Evylaeus) vulsum (Vachal). C: Lasioglossum (Evylaeus) baleicum (Cockerell). Scale: $0.5 \mathrm{~mm}$. 
with irregular sinuate ridges. Transverse carina weak dorsolaterally, indistinct dorsoapically. Lateral carinae distinct. Oblique carinae distinct, and not connected with transverse carina at upper ends. Propodeal side reticulate and weakly rugulose. Shield reticulate.

Metasomal terga weakly shiny. T1 medially with sparse fine $\mathrm{PP}(<10 \mu \varnothing)$; surface without striae. $\mathrm{T}_{2}$ basally and medially with moderately dense fine PP $(<10 \mu \varnothing)$, with weak transverse striae over the surface. T3-4 with transverse striae. Metasomal sterna weakly striate.

Male. Body length 6.6-7.0 mm, Wing length 5.4-5.7 $\mathrm{mm}(\mathrm{n}=5)$.

Color. Similar to female except as follows: labrum brown; flagellum beneath blackish brown; pronotal lobe brown; legs black or brown.

Pilosity. Similar to female except as follows: hairs on head finely branched and moderately dense; lower paraocular area and clypeus above with whitish tomentum; hairs on hind femur finely branched, sparse; hairs on T2-6 simple and short, sparse; basal hair bands absent; metasomal sterna without distinct hairs.

Structure. Similar to female except as follows.

Head length as long as head width; head length/width ratio $0.98-1.0(n=5)$. Vertex behind ocelli with coarse transverse ridges. Distance between lateral ocelli about 1.2 times distance between lateral ocellus and compound eye. Supraclypeal area weakly convex in lateral view, with moderately dense granular PP (20-30 $\mu$ ø); IS reticulate. Clypeus with moderately dense granular PP (20-30 $\mu \varnothing)$ over the surface; IS without reticulation. Basal elevation and distal process of labrum absent. Mandible edentate. Postgena with weak longitudinal striation. Scape length 0.36-0.4 mm $(n=5), F_{2}$ length about 2.5 times length of $F_{1}$.

Pronotum laterally with distinct rugulae. Mesoscutum anteriorly with cancellate PP (20-30 $\mu \varnothing)$, medially
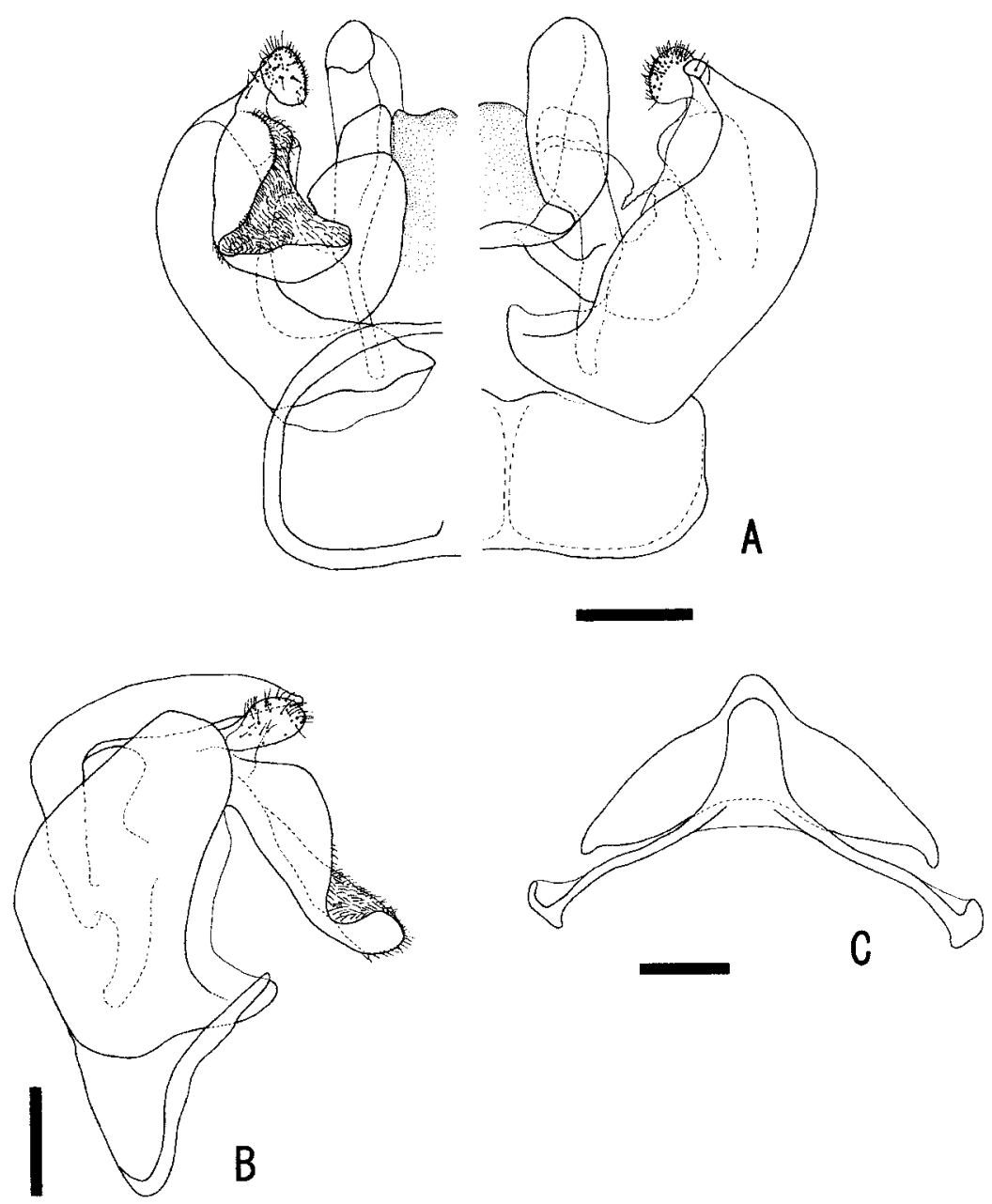

Fig. 5. A-C. Lasioglossum (Evylaeus) caliginosum sp. n., paratype. A-B: male genitalia (A: left, ventral view; right, dorsal view. B: lateral view). C: S7-8. Scale: $0.2 \mathrm{~mm}$. 
and posteriorly with dense granular PP (20-40 $\mu \varnothing)$; medially IS with weak reticulation, posteriorly IS without reticulation. Mesoscutellum, metanotum, mesepisternum and metepisternum coarsely rugulose. Basitibial plate of hind legs absent. Inner hind tibial spur without teeth. The length of propodeal dorsum about 1.5 times those of metanotum; propodeal dorsum with coarse longitudinal ridges over the surface. Transverse, oblique and lateral carinae distinct and sinuate. Propodeal side and shield coarsely rugulose.

T1 medially with sparse granular PP $(10 \mu \varnothing)$; surface without striae. T2-3 basally and medially with moderately dense granular PP $(10 \mu ø)$ and weak striae. S7 with long, apically rounded median process; $\mathrm{S} 8$ with short, apically rounded median process (Fig. 5. C).

Male Genitalia (Figs. 5. A, B; 6. A, B, G, J). Gonobasal ventral arm ring-shaped, and connected each other at upper ends in ventral view; the bottom nearly flat. The surface of gonocoxite smooth. Gonostylus (Figs.5. B; 6. A, B) ovate in ventral view, club-like in lateral view; surface with sparse spots and short hairs. Ventral retrorse lobe (Fig. 6. G) broad and long, surface with moderately dense short hairs.

Etymology. The specific name is derived from the body color as twilight at dusk.

Distribution. Far East Russia (Primorsky), Japan (Hokkaido, Honshu, Shikoku, Kyushu).

Flight records. Female: April to October. Male: Au-

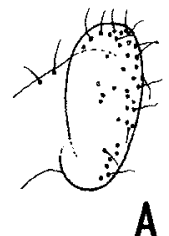

A

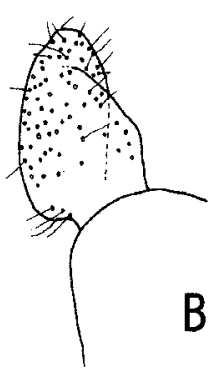

B

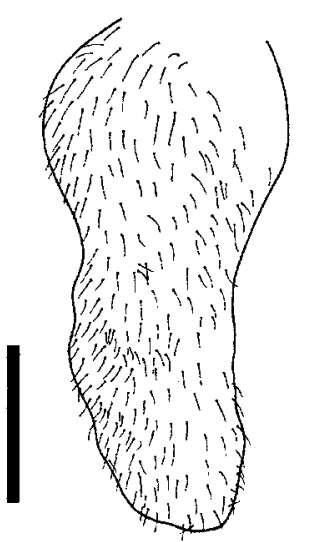

G

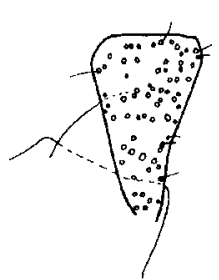

C

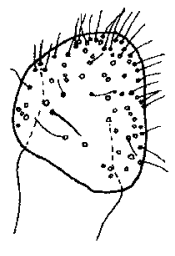

$E$
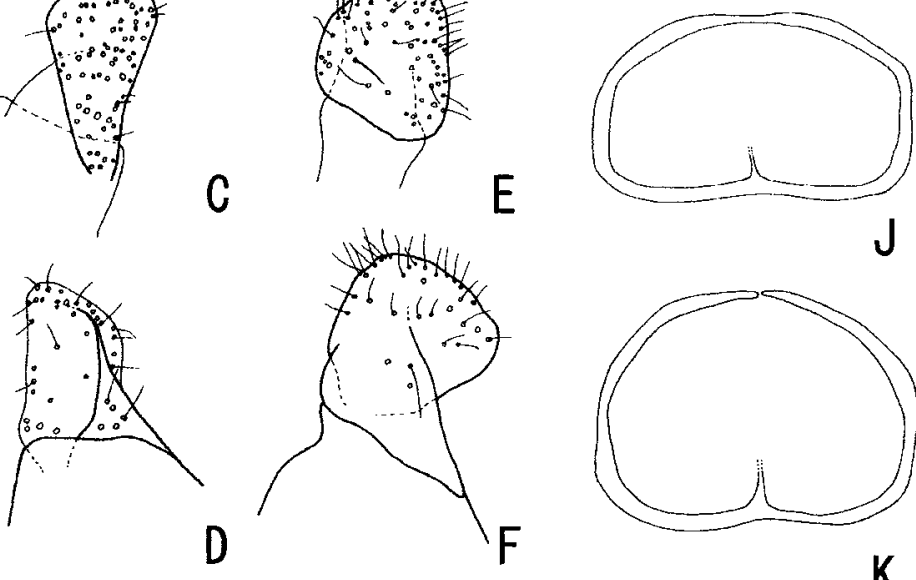

D
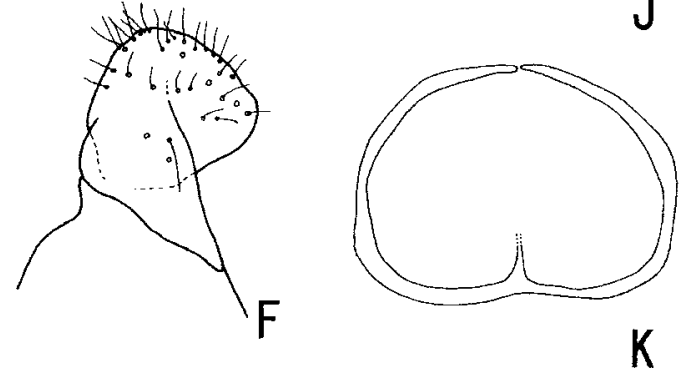

K

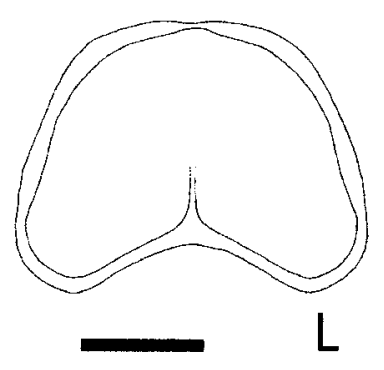

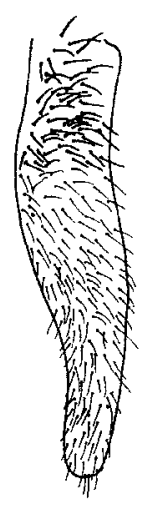

H
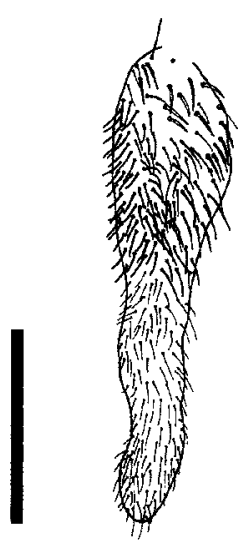

।

Fig. 6. A-L. Gonostylus, retrorse lobe and gonobasal ventral arm of male genitalia. A, B, G, J: Lasioglossum (Evylaeus) caliginosum sp. n., paratype. C, D, H, K: Lasioglossum (Evylaeus) vulsum (Vachal). E, F, I, L: Lasioglossum (Evylaeus) baleicum (Cockerell). A, C, E: gonostylus in ventral view. B, D, F: gonostylus in dorsal view. G, H, I: ventral retrorse lobe. J, K, L: gonobasal ventral arm. Scale: $0.2 \mathrm{~mm}$. 
gust to October.

Floral association. Salicaceae: Salix integra. Polygonaceae: Polygonum blumei, P. thunbergii. Berberidaceae: Berberis amurensis. Papaveraceae: Chelidonium majus. Cruciferae: Barbarea vulgaris var. stricta, Brassica campestris, Dentaria macrophylla var. dasyloba, Roripa atrovirens. Saxifragaceae: Deutzia gracilis. Rosaceae: Malus pumila var. dulcissima, Potentilla amurensis, $P$. fragarioides var. sprengeliana, Rosa rugosa. Staphyleaceae: Staphylea bumalda. Oenotheraceae: Oenothera odorata. Umbelliferae: Angelica anomala, Anthriseus nemorosa, Heracleum dulce. Primulaceae: Lysimachia vulgaris var. darurica. Caprifoliaceae: Weigela hortensis. Compositae: Anaphalis margaritacea, Aster ageratoides var. ovatus, A. glehni, Erigeron annuus, Lapsana humilis, Picris hieracioides var. japonica, Rudbeckia laciata, Taraxacum hondoense, T. officinale. Liliaceae: Gagea lutea.

Type material. Holotype: female, Botanical Garden, Sapporo, Hokkaido, Japan, 29. iv. 1959 (S. F. Sakagami leg.) (Type No. 3233).

Paratypes. [JAPAN: HOKKAIDO] 2 females, Asahikawa, 31. v., 11. viii. 1988 (T. Inaoka, SCMH); 11 females, Asahiyama, Asahikawa, 11. vi. 1966, 11. vi. 1969,25 . vi. 1969,15 . vii. 1969,30 . v. 1970, 24. vii. 1970 (SCMH); 25 females and 2 males, Botanical Garden, Sapporo, 22. iv., 6. v., 11. v., 13. v., 16. v., 17. v., 20. v., 25. v., 10. vi., 15. vi., 17. vi., 17. viii., 7. ix., 14. ix. 1959 (S. F. Sakagami, SCMH \& ECPA); 8 females, Hamakoshimizu, 10. vi. 1966, 20. vi. 1967, 10. vi. 1969, 11. vi. 1969 (S. F. Sakagami, SCMH); 41 females, Inosawa, Asahikawa, 10. v. 1969, 10. vi. 1969, 11. vi. 1969, 27. vi. 1969, 29. v. 1970, 29. v. 1979 (SCMH \& ECPA); 2 females and 2 males, Kami-Otoineppu, Nakagawa Exp. For., 7. ix. 1970 (S. F. Sakagami \& H. Fukuda, SCMH \& ECPA); 5 females, Kiritapp, 1972 (SCMH); 1 female and 9 males, Kitamoshiri, Hok. Uryu Exp. For., 10. ix., 12. ix., 14. ix. 1969 (S. F. Sakagami \& H. Fukuda, SCMH \& ECPA); 73 females, Moiwa, Sapporo, 23. v. 1970, 3. v. 1972, 9. v. 1972, 11. v. 1972, 20. v. 1972 , 23. v. 1972, 3. vi. 1972, 7. vi. 1972, 15. vi. 1972, 3. vii. 1972, 13. vii. 1972, 26. ix. 1972 (Kawano, SCMH \& ECPA); 4 females and 4 males, Nokanan, 8. vi., 22. vi., 10. viii., 11. viii., 20. ix. 1967 (SCMH \& ECPA); 4 females, Tenneru n. Kushiro, 1968 (E. Ohtsuka, SCMH); 1 female, Tobetsu, 9. vii. 1974 (M. Ishikawa, SCMH); 20 females and 2 males, Hokkaido University Campus, 1. v., 2. v., 8. v., 15. v., 25. v., 26. v., 27. v., 6. vi., 11. vi., 15. vi., 14. viii., 19. viii. 1959 (S. F. Sakagami, SCMH \& ECPA); 1 female, Yukomanbetsu, 16. v. 1967 (SCMH). [JAPAN: HONSHU]
Aomori Pref.: 1 male, Kuzukawa, Hiraka, 26. viii. 1959 (M. Yamada, SCMH); 1 female, Osaki, 10. x. 1980 (M. Yamada, SCMH); 2 females, Yasumiya, Towada-ko, 1. vi. 1987 (M. Yamada, SCMH); 1 female, Heiroku, 13. vi. 1981 (M. Yamada, SCMH); 1 female, Kaname, 8. ix. 1981 (M. Yamada, SCMH); 1 female, Mt. Bonzyu, 6. v. 1984 (M. Yamada, SCMH); 1 female, Mt. Bonzyu, Namioka, 1. v. 1983 (M. Yamada, SCMH); 1 female, Mt. Hakkoda, 11. ix. 1983 (M. Yamada, SCMH); 1 female, Mt. Herai, Shingoh, 18. vii. 1987 (M. Yamada, SCMH); 1 female, Mt. Hishikui, Azigasawa, 15. ix. 1985 (M. Yamada, SCMH); 1 female, Takinosawa, 15. vi. 1984 (M. Yamada, SCMH); 3 females, Yasumiya, Towada-ko, 1. vi. 1987 (M. Yamada, SCMH); 2 males, Mt. Iwaki, 7. ix., 5. x. 1980 (M. Yamada, SCMH). [FAR EAST RUSSIA] Primorsky: 1 female, 40kmE Ussuriysk, 13. vi. 1993 (L. V. Sidorenko, ECPA); 3 males, Ussuriyskij, Sapovednik, N43. 38.7 E132.20.8., 26-28. viii. 1999 (H. Mattes, ECPA); 1 female, Lazovski Zapovednik, Cordon Korpad, N43. 38.16.21 E134.07.49., 181m, 12. v. 2001 (M. Quest, MCMG); 2 females, Lazovski Zapovednik, Cordon Korpad, N43.17.15 E134.07.10., 526m, 13. v. 2001 (M. Quest, MCMG); 1 female, Lazovski Zapovednik, Cordon Korpad, N43.17.11. E134.07.12., 472m, 13. v. 2001 (M. Quest, MCMG); 1 female, N43.08.18 E134.08.04., 2m, 19. vii. 2001 (M. Quest, MCMG); 1 female, North of Lazo, N43.25.40 E133.52.16., 270m, 9. viii. 2001 (M. Quest, MCMG); 1 female, Cordon, N43.16.26 E134.08.26., 168m, 17. iv. 2002 (M. Quest, MCMG); 1 female, N43.01.07 E134.07.46., 0m, 4-19. viii. 2001 (M. Quest, MCMG); 1 female, Prjamushka, N43.15.52 E134.07.45., 17m, 28. v-6. vi. 2001 (M. Quest, MCMG).

Other material. [JAPAN: HOKKAIDO] 15 females, Ashorobuto, Ashoro-gun, 22. v., 23. v., 28. v., 30. v., 31. v. 1957 (M. Takahashi, ELKU); 1 female, Metou, Ashoro-gun, 19. vi. 1957 (M. Takahashi, ELKU); 1 female, Osappe, Kucharo-ko, 5. vi. 1957 (M. Takahashi, ELKU); 1 female, Asahikawa, 26. viii. 1988 (T. Inaoka, SCMH); 1 female, Higawa, 21. v. 1985 (T. Inaoka, SCMH); 2 females, Inosawa, Asahikawa, 29. v. 1970 (SCMH); 1 female, Kiritapp, 1972 (SCMH); 1 female, Kitamoshiri, Hok. Uryu Exp. For., 12. ix. 1969 (S. F. Sakagami \& H. Fukuda, SCMH); 8 females, Moiwa, Sapporo, 3. v., 23. v., 3. vi. 1972 (Kawano, SCMH). [JAPAN: HONSHU] Aomori Pref.: 3 females, Mt. Iwaki, 5. x. 1980, 16. viii. 1981 (M. Yamada, SCMH); 1 female, Towada-ko, 18. viii. 1985 (M. Yamada, SCMH); 1 female, Yasumiya, Towada-ko, 1. vi. 1987 (M. Yamada, SCMH). Nagano Pref.: 1 female, Mt. Nyugasa, 31. vii. 1962 (S. Miyamoto, ELKU). [JAPAN: KYUSHU] Fukuoka Pref.: 1 
female, Mt. Hikosan, 11. v. 1952 (Y. Hirashima, ELKU). Oita Pref.: 1 female, Mt. Kurodake, Kokonoe-machi, 25. ix. 2004 (H. Hirano).

Type depository. The holotype is deposited in the Entomological Laboratory, Faculty of Agriculture, Kyushu University (Fukuoka, Japan). The paratypes are deposited in the late Dr. S. F. Sakagami's Collection (187 females and 10 males), Ebmer's Collection (23 females and 12 males) and M. Quest's Collection (9 females).

\section{Lasioglossum (Evylaeus) miyabei sp. $\mathbf{n}$.}

(Figs. 7. A-G; 8. A, B; 9. A-F; 12. A; 13. B)

\section{Diagnosis}

Female: the shape of head clearly transverse-oval; the suplaclypeal area and the basal part of clypeus weakly shiny, with weak reticulation; the mesoscutum medially with sparse PP, laterally with dense PP; the mesepisternal IS weakly reticulate; the lateral parts of propodeum rounded at the end, without ridge; the metasomal terga without distinct sculpture. Male: the shape of head similar to female; the mesoscutum medially with equable PP, to the lateral parts the distance between PP becomes denser; the propodeal dorsum with sinuate ridges, at the end with fine border; the lateral parts of propodeum without ridge; the distal parts of metasomal sterna (Fig. 12. A) simple; the $\mathrm{S}_{4-6}$ with inconspicuous, short and sparse hairs; the gonostylus (Fig. 9. C, D) club-like, similar to Lasioglossum atroglaucum (Strand, 1913) (See Ebmer et al. 1994: Fig. 18); the ventral retrorse lobe (Fig. 9. E) slender, with hairs in form of eyelash.

This species is closely similar to Lasioglossum yamanei sp. $\mathrm{n}$. in having the following morphological characters: the head and mesosoma with weak bluegreenish metallic luster in female and male and the similar sculpture of head and thorax in female and male. But this species can be distinguished from L. yamanei by the

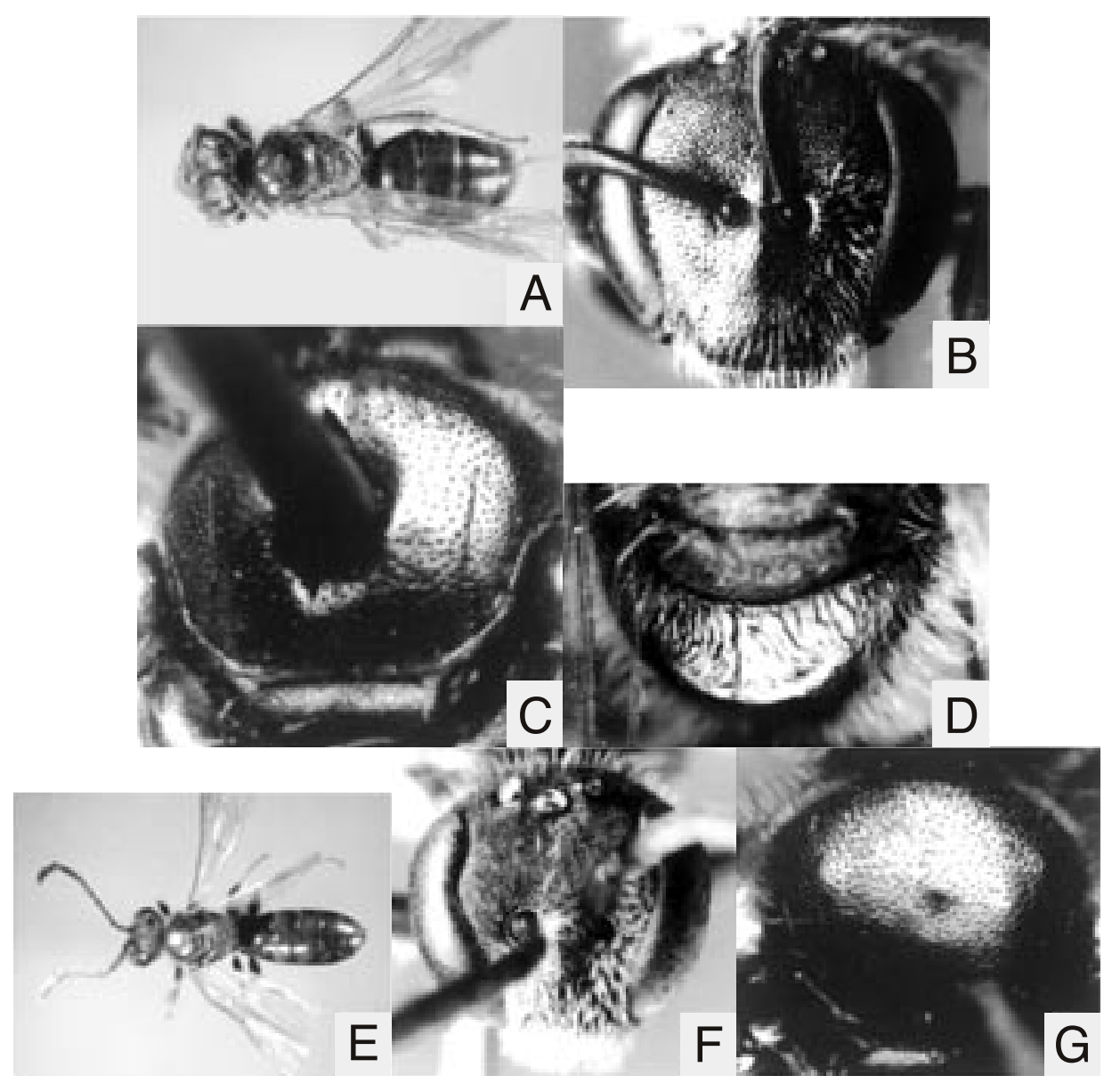

Fig. 7. A-G. Lasioglossum (Evylaeus) miyabei sp. n. Female, holotype: A, general habitus; B, head in frontal view; $\mathrm{C}$, mesoscutum; D, propodeal dorsum. Male, paratype: E, general habitus; F: head in frontal view; G, mesoscutum. 
transverse head in female; the shape of the distal process of female labrum (Fig. 8. A, C), the tibiae above and below yellow in male; the metasomal terga dimly shiny and the $\mathrm{T}_{1}$ medially and posteriorly with weak transverse striae in the female, and the shape of $\mathrm{S}_{5}$ and genitalia in male (Figs. 9. A-E; 11. A-C; 12. A, B).

\section{Description}

Female. Body length 5.9-6.6 mm, Wing length 5.2$5.7 \mathrm{~mm}(\mathrm{n}=5)$.

Color. Head and mesosoma with weak blue-greenish metallic luster. Head: mandible with apical half reddish brown; flagellum beneath yellowish brown. Mesosoma: pronotal lobe brown; tegula yellowish brown transparent; wings nearly transparent; veins and pterostigma yellowish brown; legs brown to yellowish brown; tibial spur yellow. Metasoma: posterior margins of metasomal terga broadly yellowish brown transparent.

Pilosity. Body hairs whitish and pale yellowish. Hairs on head finely branched excluding clypeus; hairs on clypeus simple, sparse. Hairs on mesosoma finely branched except as follows: lateral lobe of pronotum and medial area of metanotum with dense tomentum; hind femur with plumose hairs, forming scopa. Anterior and lateral hairs on $\mathrm{T}_{1}$ finely branched, sparse. Hairs on $\mathrm{T}_{2}-4$ simple and short, sparse. Hairs on T5 finely branched, dense. Basal hair bands absent. Hairs on metasomal sterna finely branched, moderately dense.

Structure. Head width longer than head length; head length/width ratio 0.91-0.94 $(\mathrm{n}=10)$. Vertex behind ocelli with weak transverse ridges. Distance between lateral ocelli slightly longer than distance between lateral ocellus and compound eye. Frons weakly shiny and nearly flat, with cancellate PP $(20 \mu \varnothing)$. Paraocular area weakly shiny, with cancellate PP (20-30 area slightly convex in lateral view, weakly shiny, with moderately dense granular PP $(20 \mu \varnothing)$; IS reticulate. Clypeal length as long as the distance between lower rim of antennal socket and upper margin of clypeus. Clypeus nearly flat, weakly shiny, its surface with moderately dense granular PP $(20 \mu \varnothing)$; IS reticulate above, scarcely reticulate below. Basal area of labrum about 2.4 times as wide as long; basal elevation well developed; lateral projection of distal process absent; keel of distal process moderately broad, apically pointed in frontal view; labral fimbria all acutely pointed at apex. Mandible bidentate. Hypostomal carina moderately developed; anterior angle of hypostomal carina obtuse. Postgena shiny and weakly reticulate. Genal area with oblique ridges. Scape length $0.7-0.76 \mathrm{~mm}(\mathrm{n}=5), \mathrm{F}_{1}$ length as long as $\mathrm{F}_{2}$.

Pronotum with dorsolateral angle obtuse; lateral sul-

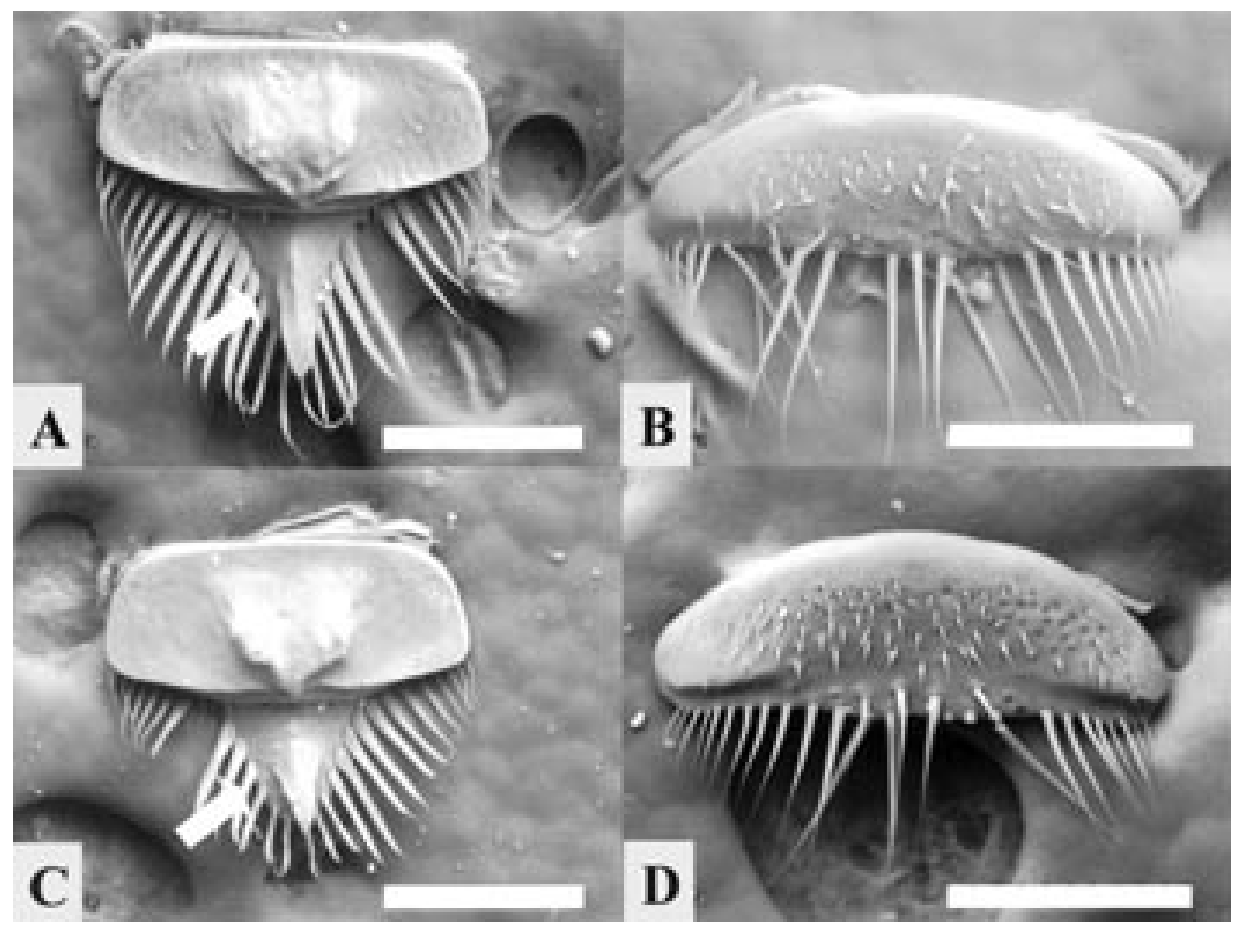

Fig. 8. A-D. Labrum, paratype. Lasioglossum (Evylaeus) miyabei sp. n.: A, female; B, male. Lasioglossum (Evylaeus) yamanei sp. n.: C, female; D, male. Scale: $0.2 \mathrm{~mm}$. 
cus distinct; lateral surface rugulose. Mesoscutum weakly shiny, with moderately dense granular PP (10-20 $\mu \varnothing)$; IS anteriorly with weak reticulation, IS medially and posteriorly without reticulation. Mesoscutellum nearly flat, its sculpture similar to mesoscutum. Metanotum weakly shiny and rugulose. Mesepisternum above shiny, its surface nearly smooth; below weakly shiny, with rugoso-punctures (20-40 $\mu \varnothing)$; IS with weak reticulation. Metepisternum with transverse ridges in upper half, with weak rugulae in lower half. Basitibial plate of hind legs ovate, pointed apically. Inner hind tibial spur with 3-5 teeth $(n=90)$. The length of propodeal dorsum as long as mesoscutellum, and about 1.8 times those of metanotum; propodeal dorsum gently inclined; propodeal dorsum with distinct longitudinal ridges not exceeding to posterior margin. Transverse and oblique carinae absent. Shield with lateral carinae at lower half. Propodeal side and shield distinctly reticulate.

Metasomal terga dimly shiny and nearly impunctate. $\mathrm{T}_{1}$ medially and posteriorly with weak transverse striae. T2-4 and metasomal sterna with weak transverse striae over the surface.

Male. Body length 5.8-6.2mm, Wing length 4.8 $5.6 \mathrm{~mm}(\mathrm{n}=5)$.

Color. Similar to female except as follows: lower half of clypeus yellow; mandible apically reddish brown and medially yellow; labrum brown; legs brown and yellow; tibiae above and below yellow; tibial spur and tarsi yellow.

Pilosity. Similar to female except as follows: lower paraocular area with moderately dense tomentum; clypeus with sparse tomentum; metanotum without tomentum; hind femur with sparse fine branch hairs; hairs on T5 simple and short, sparse; hairs on metasomal sterna simple and short, and mixed with a few fine branch hairs.

Structure. Similar to female except as follows.

Head length/width ratio 0.94-0.98 $(n=10)$. Vertex behind ocelli with weak rugulae. Distance between lateral ocelli about 1.2 times distance between lateral ocellus and compound eye. Frons dull. Clypeal length about 1.2 times the length between lower rim of antennal socket and upper margin of clypeus. Clypeal IS scarcely reticulate. Basal area of labrum about 3.5 times as wide as long; basal elevation and distal process of labrum absent. Mandible edentate. Scape length $0.36 \mathrm{~mm}(\mathrm{n}=5)$, $F_{1}$ length about 2 times $F_{2}$.

Mesoscutum shiny. Mesoscutellum slightly convex. Mesepisternum with granular PP, sparse above and moderately dense below; IS without reticulation. Basitibial plate of hind legs absent. Inner hind tibial spur without teeth. The length of propodeal dorsum as long as mesoscutellum, and about 1.3 times those of metanotum; propodeal dorsum medially with sinuate ridges. Propodeal side with rugulae and distinct reticulation.

Metasomal terga weakly shiny. T1 without striation; medially with ill-defined PP, sparse. T2-3 basally and posteriorly with weak transverse striae; medially with ill-defined PP, moderately dense. T4-5 with weak transverse striae over the surface. $\mathrm{S} 7$ with short, apically rounded median process; $\mathrm{S} 8$ without median process (Fig. 9. F).

Male Genitalia (Figs. 9. A-E). Gonobasal ventral arm ring-shaped, not connected each other at upper ends in ventral view; the bottom nearly flat. Surface of gonocoxite smooth. Gonostylus (Fig. 9. C, D) club-like in ventral and lateral view; surface with moderately dense spots and sparse short hairs. Ventral retrorse lobe (Fig. 9. E) slender, surface with sparse short hairs. Penis valve round apically.

Etymology. The specific name is dedicated to Dr. Kingo Miyabe in accordance with the desire of the late Dr. S. F. Sakagami. Dr. Miyabe founded the Botanical Garden of Hokkaido University, Sapporo where Dr. Sakagami investigated the nest of this species for the first time.

Distribution. Far East Russia (Primorsky), Japan (Hokkaido, Honshu, Shikoku, Kyushu, Yaku-shima Is.).

Flight records. Female: April to October. Male: July to October.

Floral association. Polygonaceae: Polygonum sachalinense, P. thunbergii. Ranunculaceae: Anemone flaccida, Cimicifuga yesoensis. Cruciferae: Barbarea vulgaris var. stricta, Brassica campestris, Dentaria macrophylla var. dasyloba, Rophanus sativus var. acanthiformis. Saxifragaceae: Deutzia crenata. Rosaceae: Crataegus cuneata, Malus pumila var. dulcissima, Spiraea cantoniensis. Leguminosae: Robinia pseudo-Acacia, Trifolium pratense. Geraniaceae: Geranium nepalense. Celastraceae: Euonymus alata forma striata. Araliaceae: Aralia cordata. Umbelliferae: Anthriscus nemorosa, Foeniculum vulgare, Heracleum dulce, H. lanatum. Scrophulariaceae: Veronicastrum sibiricum var. japonicum. Compositae: Aster ageratoides var. ovatus, A. glehni, Cirsium kamtschaticum, Cosmos bipinnatus, Erigeron annuus, Hieracium japonicum, Picris hieracioides var. japonica, Petasites japonicus giganteus, Rudbeckia laciniata, Senecio palmatus, Solidago virga-aurea, Taraxacum officinale. Liliaceae: Allium tuberosum, Gagea lutea.

Type material. Holotype: female, Botanical Garden, Sapporo, Hokkaido, Japan, 4. vi. 1959 (S. F. Sakagami 

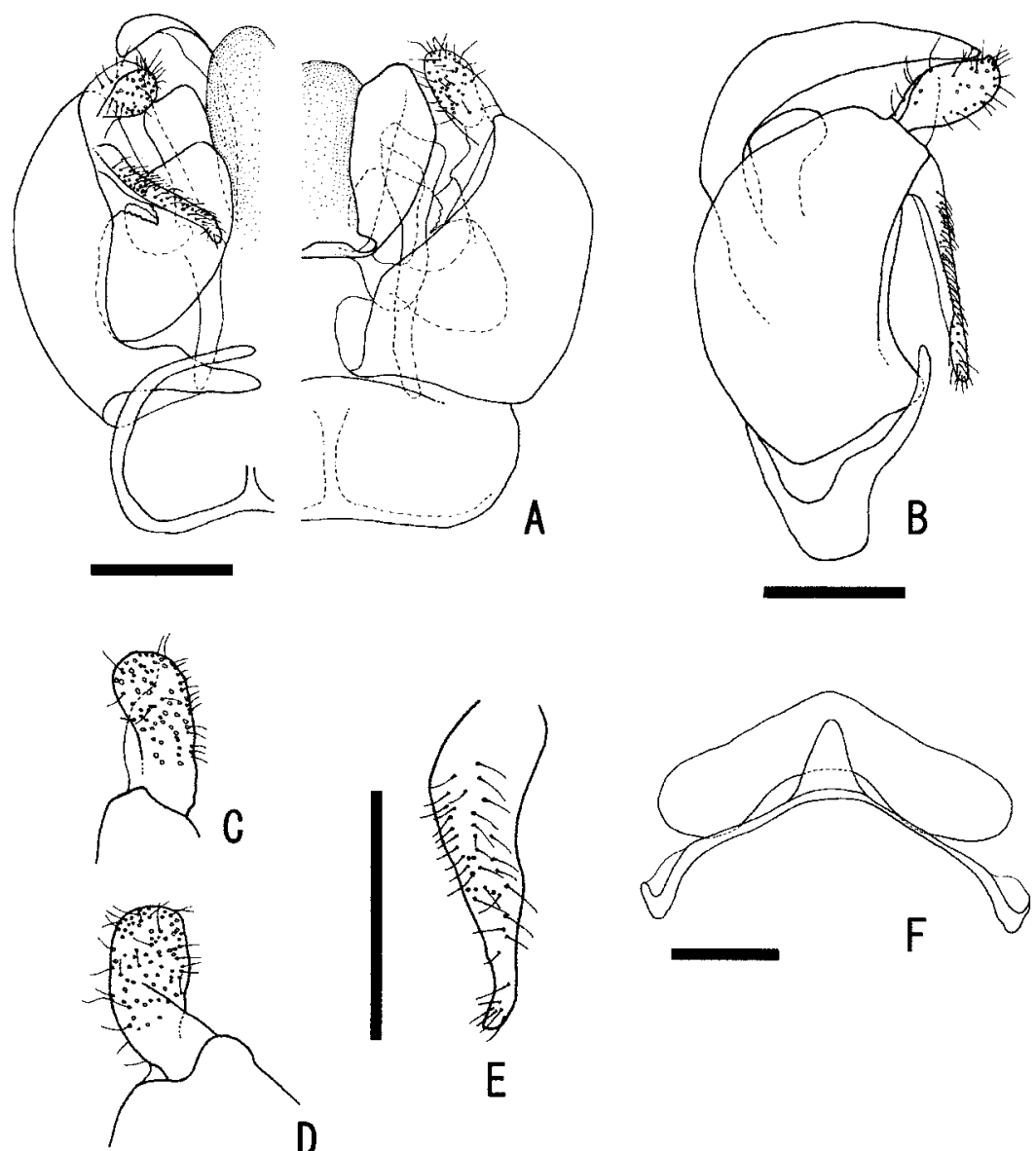

Fig. 9. A-F. Lasioglossum (Evylaeus) miyabei sp. n., paratype. A-E: Male genitalia (A: left, ventral view; right, dorsal view. B: lateral view. C: gonostylus in ventral view. D: gonostylus in dorsal view. E: ventral retrorse lobe. F: S7-8 Scale: A-E, 0.2mm.

leg.) (Type No. 3234).

Paratypes. [JAPAN: HOKKAIDO] 54 females and 25 males, Botanical Garden, Sapporo, 21. iv., 22. iv., 29. iv., 6. v., 7. v., 20. v., 22. v., 23. v., 25. v., 4. vi., 10. vi., 15. vi., 22. vi., 29. vi., 1. vii., 8. vii., 14. vii., 20. vii., 31. viii., 7. ix., 8. ix., 14. ix. 1959 (S. F. Sakagami, SCMH \& ECPA); 1 male, Kitamoshiri, Hok. Uryu Exp. For., 12. ix. 1969 (S. F. Sakagami \& H. Fukuda, SCMH); 1 female, Higawa, 2. v., 1985 (T. Inaoka, SCMH); 26 females, Inosawa, Asahikawa, 10. v. 1969, 10. vi. 1969, 29. v. 1970 (SCMH); 10 females and 23 males, KamiOtoineppu, Nakagawa Exp. For., 6. ix., 7. ix. 1970 (S. F. Sakagami \& H. Fukuda, SCMH \& ECPA); 1 female and 7 males, Makkari, 7. x. 1961 (S. F. Sakagami, SCMH); 1 female, Metou, Ashoro-gun, 19. vi. 1957 (M. Takahashi, $\mathrm{SCMH}) ; 1$ female and 1 male, Moiwa, Sapporo, 3. vi., 26. ix. 1972 (Kawano, SCMH); 1 female, Mt. Popouyama, Kucharo, 16. vi. 1960 (S. F. Sakagami, SCMH); 1 female and 2 males, Nishiashoro, Tokachi, 9. vii., 9. viii. 1955 (Y. Hirashima \& S. F. Sakagami, SCMH); 6 females and 2 males, Nokanan, 6. vii., 21. vii., 10. viii., 11. viii., 20. ix. 1967 (SCMH); 2 females, Tenneru n. Kushiro, 1968 (E. Ohtsuka, SCMH); 2 females, Yukomanbetsu, 16. v. 1967 (SCMH). [JAPAN: HONSHU] Aomori Pref.: 1 male, Mt. Hishikui, Asigasawa, 15. ix. 1985 (M. Yamada, SCMH); 1 female, Heiroku, 13. vi. 1981 (M. Yamada, SCMH); 2 females, Itadome, 27. v., 13. vi. 1981 (M. Yamada, SCMH); 1 female, Kohseirindo, Nishimeya, 10. viii. 1985 (M. Yamada, SCMH); 1 female, Minami-hakkoda, Hiraka, 17. viii. 1984 (M. Yamada, SCMH); 1 female, Mt. Hakkoda, 11. ix., 1983 (M. Yamada, SCMH); 2 females and 2 males, Mt. Herai, Shingoh, 14. vi. 1986, 18. vii. 1987, 29. viii. 1987 (M. Yamada, SCMH); 2 females, Mt. Kuromori, 31. v., 25. vi., 1981 (M. Yamada, SCMH); 1 female and 3 males, Mt. Ohkuromori, Takko, 30. viii., 13. ix., 1987 (M. Yamada, SCMH); 1 female, Oh-kawa, Nishimeya, 23. ix. 1985 (M. Yamada, SCMH); 2 females, Shiroiwa, 
Hiraka, 22.vi. 1985 (M. Yamada, SCMH); 1 female, Shiroiwa, Onoi, 2. vi., 1985 (M. Yamada, SCMH); 2 females, Yasumiya, Towada-ko, 1. vi., 7. viii., 1987 (M. Yamada, SCMH); 4 females, Zatoish, Hirosaki, 19. v. 1983, 6. vi. 1984 (M. Yamada, SCMH \& ECPA). Fukui Pref.: 1 female, Kyo-ga-take, Ohno, 17. ix. 1982 (Y. Haneda, SCMH); 1 female, Suwara, Ohno, 12. v. 1984 (Y. Haneda, SCMH). Ishikawa Pref.: 1 female, Shiramine, 19. iv. 1985 (Y. Haneda, SCMH). Kyoto Pref.: 1 female, Kamitani, Ashu, 8. vi. 1986 (M. Kato, SCMH). [FAR EAST RUSSIA] Primorsky: 1 male, Lazo, Karpath-Hütte, N43.15.8 E134.07.9., 22. viii. 1999 (H. Mattes, ECPA); 1 female, Lazo, N43.17.15 E134. 07.10., 526m, 13. v-5. vi. 2001 (M. Quest, MCMG); 1 female, Lazo, Prjamushka, N43.15.47 E134.07.44., $175 \mathrm{~m}, 28$. v-6. vi. 2001 (M. Quest, MCMG); 1 male, N43.17.16 E134.07.09., 506 m, 24. viii-18. ix. 2001 (M. Quest, MCMG); 1 male, N43.01.17 E134.08.04., 3m, 5. x. 2001 (M. Quest, MCMG).

Other material. [JAPAN: HOKKAIDO] 2 females, Ashorobuto, Ashoro-gun, 28. v. 1957 (M. Takahashi, ELKU); 1 female, Sapporo, 5. v. 1947 (S. F. Sakagami, ELKU); 2 males, Sapporo, 8. ix. 1958 (S. Ueda, ELKU); 1 male, Sapporo, 13. viii. 1955 (Y. Hirashima, ELKU). 2 females, Kawakami, near Honbetsu, 17-27. vii. 1953 (Y. Hirashima, ELKU); 2 females, Piuka (Teshio), 22. vii. 1952 (T. Shirôzu, ELKU); 2 females, Asahiyama, Asahikawa, 15. vii. 1969, 30. v. 1970 (SCMH); 2 females, Nishiashoro, 9. viii. 1955 (Y. Hirashima, ELKU); 6 females, Nibushi, Kushiro, 1-2. vii. 1960 (S. Nakano, ELKU); 1 male, Nishiashoro, Tokachi, 9. viii. 1955 (Y. Hirashima, ELKU). 5 females, Osappe, Kucharo-ko, 5. vi. 1957 (M. Takahashi, ELKU). 4 females, Botanical Garden, Sapporo, 11. v., 4. vi., 22. ix. 1959 (S. F. Sakagami, SCMH); 1 female, Botanical Garden, Sapporo, 27. vi. 1958 (Y. Hirashima, ELKU); 2 females, Inosawa, Asahikawa, 10. vi. 1969, 29. v. 1970 (SCMH); 4 females and 1 male, Kami-Otoineppu, Nakagawa Exp. For., 6. ix., 7. ix. 1970 (S. F. Sakagami \& H. Fukuda, SCMH); 1 male, Kitamoshiri, Hok. Uryu Exp. For., 12. ix. 1969 (S. F. Sakagami \& H. Fukuda, SCMH); 1 female, Nokanan, 8. vi. 1967 (SCMH). [JAPAN: HONSHU] Aomori Pref.: 1 female, Sugayu, Mt. Hakkoda, 30. v. 1975 (O. Tadauchi, ELKU). 1 male, Natsusaka, Takko, 19. ix. 1983 (M. Yamada, SCMH); 1 female, Itadome, 13. vi. 1981 (M. Yamada, SCMH); 1 female, Kuromori, 23. vi. 1981 (M. Yamada, SCMH); 1 female, Zatoish, Hirosaki, 22. vi. 1984 (M. Yamada, SCMH). Tochigi Pref.: 1 female, Shichiri, Nikko, 11. v. 1976 (O. Tadauchi, ELKU); 5 females, Lake Chuzenji, Nikko, 11. v. 1976 (O. Tadauchi, ELKU); 1 female, Nikko, 14. vii. 1956 (S. Ki- moto, ELKU). Yamanashi Pref.: 2 females and 4 males, Masutomi, 30. viii., 3. ix., 5. ix., 8. ix. 1975 (J. Emoto, ELKU). Nagano Pref.: 2 females, Mt. Shirouma, Oyanohara, 15. v. 1976 (O. Tadauchi, ELKU). Gifu Pref.: 34 females, Mt. Norikura, Hatahoko, 8. v. 1976 (O. Tadauchi, ELKU). Kyoto Pref.: 2 females, Kamitani, Ashu, 27. vi. 1985, 8. vi. 1986 (M. Kato, SCMH). Wakayama Pref.: 1 female, Mt. Koya, Koya-machi, 27. iv. 1976 (O. Tadauchi, ELKU). [JAPAN: KYUSHU] Oita Pref.: 1 female, Mt. Kurodake, Kokonoe-machi, 25. ix. 2004 (H. Hirano). Kagoshima Pref.: 1 female, Kosugidani, Yaku-shima Is., 25. iv. 1929 (Takeuchi, ELKU); 1 female, Yaku-shima Is., 27. iv. 1929 (Takeuchi, ELKU). 1 female, Anbo, Yaku, Yaku-shima Is., 29. iv. 2005 (O. Tadauchi).

Type depository. The holotype is deposited in the Entomological Laboratory, Faculty of Agriculture, Kyushu University (Fukuoka, Japan). The paratypes are deposited in the late Dr. S. F. Sakagami's Collection (128 females and 59 males), Ebmer's Collection ( 9 females and 8 males), and M. Quest's Collection (2 females and 2 males).

\section{Lasioglossum (Evylaeus) yamanei sp. $\mathbf{n}$.}

(Figs. 8. C, D; 10. A-G; 11. A-D; 12. B; 13. C)

\section{Diagnosis}

Female: the sculpture of supraclypeal area and clypeus similar to Lasioglossum miyabei sp. n.; the mesoscutum medially with sparse PP; the mesepisternum shiny, marginally with weak reticulation; the metasomal terga without distinct sculpture. Male: the clypeus more extend than in L. miyabei (Figs. 7. F; 10. F); the $\mathrm{S}_{4}$ with a few, short and erect hairs; S5 medially with apical depression; the $\mathrm{S} 6$ with short and appressed hairs (the distal parts of metasomal sterna see Fig. 12. B); the gonostylus (Fig. 11. A-C) large-sized, with long bristle, similar to $L$. virideglaucum Ebmer et Sakagami; the ventral retrores lobe (Fig. 11. A) short, with short bristle and hairs.

\section{Description}

Female. Body length 5.7-6.3 mm, Wing length $4.7-$ $5.3 \mathrm{~mm}(\mathrm{n}=5)$.

Color. Head and mesosoma with weak blue-greenish metallic luster. Mandible with apical half reddish brown; flagellum beneath brown; tegula yellowish brown transparent; wings nearly transparent; veins yellowish brown; pterostigma brown; legs brown; tibial spur yellow; posterior margins of metasomal terga broadly yellowish brown transparent.

Pilosity. Body hairs whitish and pale yellowish. Hairs 
on head finely branched, sparse. Hairs on mesosoma finely branched except as follows: pronotal dorsum, lateral lobe of pronotum and medial area of metanotum with dense tomentum; hind trochanter and femur with plumose hairs forming scopa. Anterior and lateral hairs on $\mathrm{T}_{1}$ finely branched, sparse. Hairs on $\mathrm{T}_{2}$ simple and short, sparse. Hairs on T3-4 simple and short, moderately dense. Hairs on T5 finely branched, moderately dense. Basal hair bands absent. Hairs on metasomal sterna finely branched, moderately dense, and mixed with a few simple hairs.

Structure. Head width as long as head length; head length/width ratio 0.98-1.03 $(\mathrm{n}=10)$. Vertex behind ocelli with weak rugulae. Distance between lateral ocelli as long as distance between lateral ocellus and compound eye. Frons and paraocular area weakly shiny and nearly flat, with cancellate PP (20-30 $\mu$ ø); IS of paraocular area reticulate. Supraclypeal area slightly convex in lateral view, weakly shiny, with sparse granular PP (20 $\mu \varnothing)$; IS distinctly reticulate. Clypeal length about 1.3 times the distance between lower rim of antennal soclet and upper margin of clypeus. Clypeus nearly flat, weakly shiny, its surface with sparse granular PP (20-30 $\mu$ ø); IS reticulate above, scarcely reticulate below. Basal area of labrum about 2.3 times as wide as long; basal elevation well developed; lateral projection of distal process absent; keel of distal process apically pointed in frontal view; labral fimbria all acutely pointed at apex. Mandible bidentate. Hypostomal carina moderately developed; anterior angle of hypostomal carina obtuse. Postgena reticulate and obliquely striate. Genal area with oblique ridges. Scape length 0.64-0.68 mm ( $\mathrm{n}=5), \mathrm{F}_{1}$ length as long as $\mathrm{F}_{2}$.

Pronotum with dorsolateral angle obtuse; lateral sulcus distinct; lateral surface with weak rugulae. Mesoscutum shiny, with moderately dense granular PP

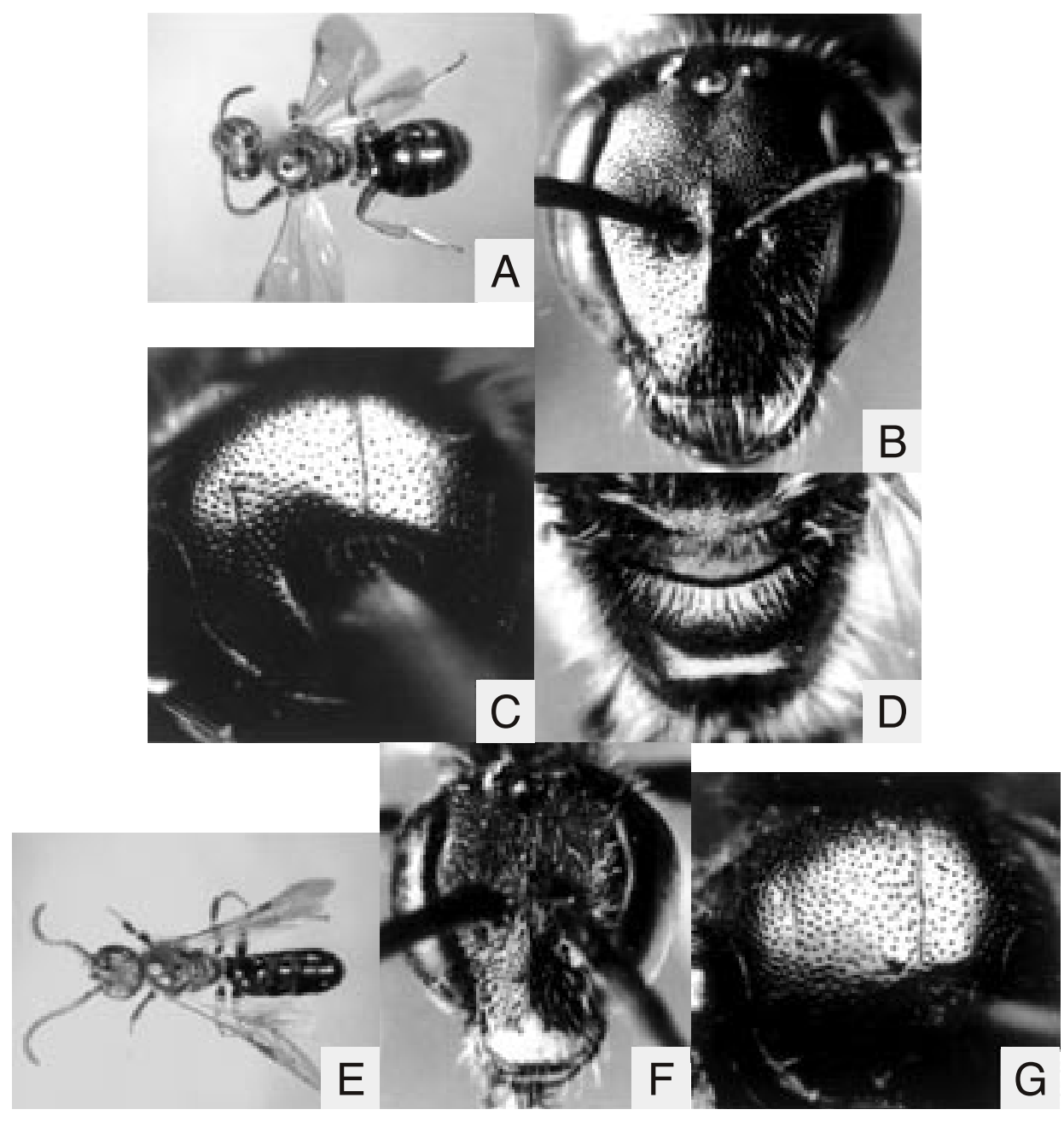

Fig. 10. A-G. Lasioglossum (Evylaeus) yamanei sp. n. Female, holotype: A, general habitus; B, head in frontal view; C, mesoscutum; D, propodeal dorsum. Male, paratype: E, general habitus; F, head in frontal view; G, mesoscutum. 
(15-20 $\mu \varnothing)$ over the surface; IS anteriorly with reticulation, medially and posteriorly without reticulation. Mesoscutellum nearly flat, with moderately dense granular PP (15-20 $\mu \varnothing)$; IS marginally with weak reticulation, IS medially without reticulation. Metanotum dull, weakly rugulose. Mesepisternum shiny, with granular PP (15-30 $\mu \varnothing)$, sparse PP above, moderately dense PP below; marginally with weak reticulation. Metepisternum with weak transverse ridges in upper half, with weak rugulae in lower half. Basitibial plate of hind legs ovate, pointed apically. Inner hind tibial spur with 2-4 teeth $(n=23)$. The length of propodeal dorsum as long as mesoscutellum, and about 1.5 times those of metanotum; propodeal dorsum gently inclined; propodeal dorsum with ridges from basal to medial, and with reticulation from medial to posterior. Transverse carina absent. Lateral and oblique carinae weak. Propodeal side rugulose. Shield reticulate.

Metasomal terga weakly shiny. $\mathrm{T}_{1}$ nearly smooth over the surface. $T_{2}$ basally and medially with ill-defined PP; IS basally and posteriorly with weak transverse striae. T3-4 with weak transverse striae over the surface. Metasomal sterna weakly striate.

Male. Body length 5.9-6.4mm, Wing length 5.2mm $(\mathrm{n}=5)$.

Color. Similar to female except as follows: lower half of clypeus yellow; flagellum beneath yellowish brown.

Pilosity. Similar to female except as follows: paraocular and supraclypeal areas with sparse tomentum; pronotal dorsum, medial area of metanotum, hind trochanter and hind femur with sparse fine branch hairs; hairs on metasomal sterna finely branched, sparse.

Structure. Similar to female except as follows.

Head length longer than head width; head length/ width ratio 1.05-1.08 $(n=10)$. Vertex behind ocelli with rugulae. Distance between lateral ocelli about 1.3 times distance between lateral ocellus and compound eye. Frons and paraocular area dull. Supraclypeal area dull, slightly convex in lateral view. Clypeus with sparse granular PP (20-30 $\mu \varnothing)$; IS reticulate over the surface. Basal area of labrum about 2.3 times as wide as long; basal elevation and distal process of labrum absent. Mandible edentate. Postgena reticulate over the surface. Scape length 0.36-0.38 mm $(n=5), F_{2}$ length about 2 times $\mathrm{F}_{1}$

Mesoscutellum with dense granular PP (20-30 $\mu$ ø); IS without reticulation. Basitibial plate of hind legs absent. Inner hind tibial spur without teeth. Length of propodeal dorsum about those of 1.8 times metanotum; propodeal dorsum with longitudinal ridges not exceeding posterior margin. Oblique carina absent. Shield with lateral carinae at lower half.

$\mathrm{T}_{1}$ without striae over the surface; medially with sparse fine $\mathrm{PP}(<10 \mu \varnothing)$. T2-3 basally and medially with moderately dense fine PP $(<10 \mu \varnothing)$; surface basally and posteriorly with weak striae. S5 medially with apical depression (Fig. 12. B). S7 with slender, apically rounded median process; $\mathrm{S} 8$ without median process (Fig. 11. D).

Male Genitalia (Fig. 11. A-C). Gonobasal ventral arm ring-shaped, not connected each other at upper ends in ventral view; bottom slightly depressed. Surface of gonocoxite smooth. Gonostylus (Fig. 11. A-C) large-sized, truncated apically in lateral view; surface with moderately dense long bristle, and mixed with a few short bristle and hairs. Ventral retrorse lobe short, surface with moderately dense short bristle and hairs. Upper ends of penis valve extend in ventral and dorsal views, and distinctly convex in lateral view.

Etymology. The specific name is dedicated to Prof. S. Yamane (Ibaraki University) in accordance with the desire of the late Dr. S. F. Sakagami.

Distribution. Japan (Honshu, Shikoku, Kyushu).

Flight records. Female: April to October. Male: August to October.

Floral association. Polygonaceae: Polygonum thunbergii. Caryophyllaceae: Stellaria sessiliflora. Cruciferae: Brassica campestris, Capsella bursa-pastoris, Dentaria macrophylla var. dasyloba, Wasabia tenuis. Rosaceae: Duchesnea chrysantha, Rubus palmatus. Geraniaceae: Geranium paniculata. Violaceae: Viola obtusa. Umbelliferae: Osmorhiza aristata. Ericaceae: Tripetaleia paniculata. Compositae: Aster glehni, Lactuca laciniata, Solidago virga-aurea.

Type material. Holotype: female, Mt. Yamizo, Ibaraki Pref., Japan, 6. ix. 1978 (H. Ishii leg.) (Type No. 3235).

Paratypes. [JAPAN: HONSHU] Aomori Pref.: 9 males, Akagawa, Shimokita, 5. x., 17. x. 1968 (Y. Harada, SCMH \& ECPA). Fukui Pref.: 1 female, Katsuyama, Ohara, 13. vi. 1986 (Y. Haneda, SCMH); 1 female, Suwara, Ohno, 25. iv. 1983 (Y. Haneda, SCMH). Ibaraki Pref.: 1 female, Mt. Tsukuba, 8. v. 1978 (Y. Ojima, SCMH); 12 females and 9 males, Mt. Yamizo, 8. v., 16. v., 28. vii., 6. viii., 13. viii., 26. viii., 26. ix., 28. ix., 22. x., 31. x. 1978 (H. Ishii, SCMH \& ECPA); 10 females, Mt. Yamizo, Daigo, 26. iv., 3. v., 16. v., 26. v., 30. v. 1978 (H. Ishii, SCMH \& ECPA). Ishikawa Pref.: 1 female, Shiramine, 21. iv. 1985 (Y. Haneda, SCMH).

Other material. [JAPAN: HONSHU] Aomori Pref.: 1 female, Mt. Ohkuromori, Takko, 13. ix. 1987 (M. Yamada, SCMH); 3 males, Akagawa, Shimokita, 26. 

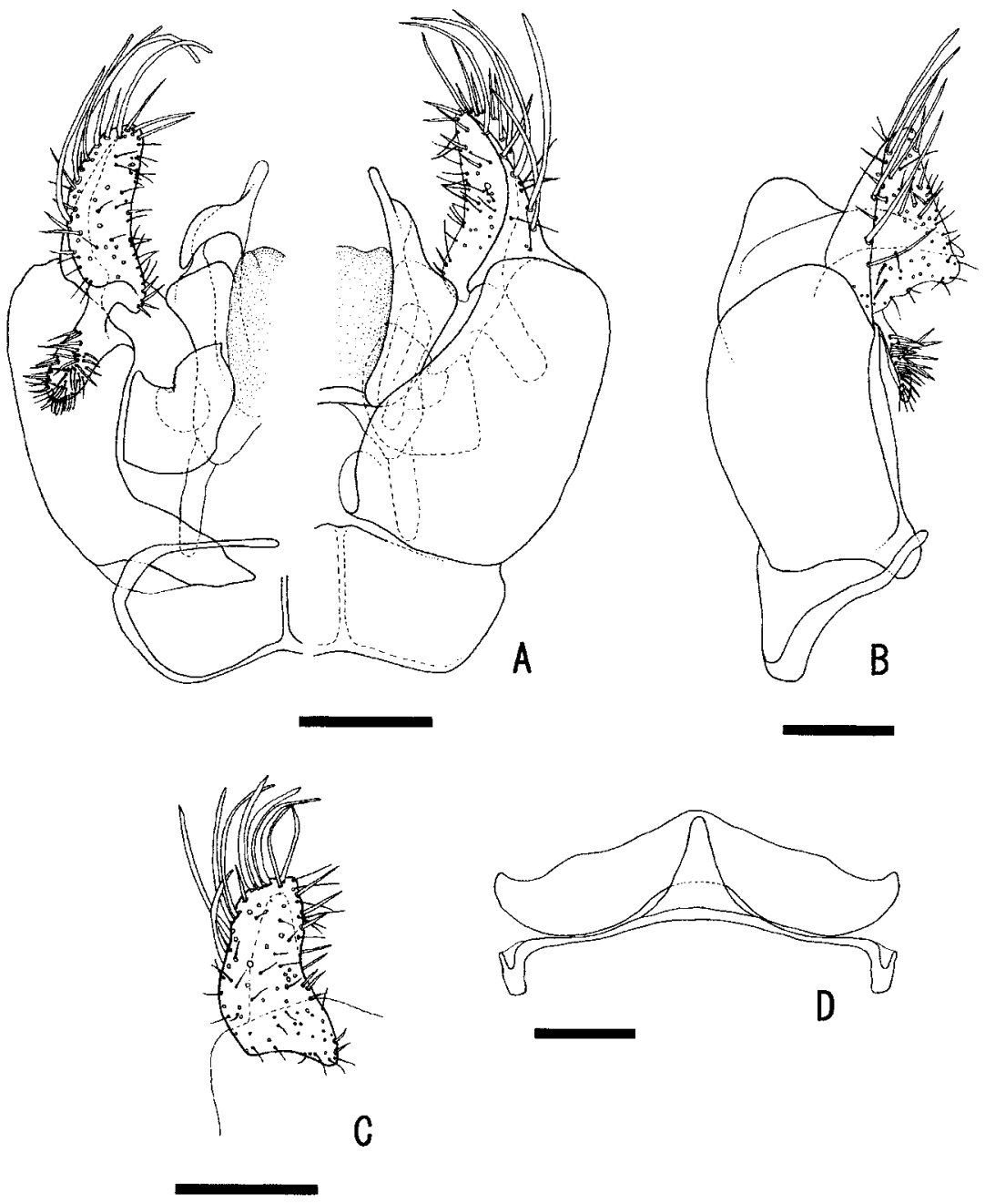

Fig. 11. A-D. Lasioglossum (Evylaeus) yamanei sp. n., paratype. A-C: Male genitalia (A: left, ventral view; right, dorsal view. B: lateral view. C: gonostylus in ventral view). D: S7-8. Scale: $0.2 \mathrm{~mm}$.

viii., 17. x. 1968 (Y. Harada, SCMH). Tochigi Pref.: 45 females, Shichiri, Nikko, 11. v. 1976 (O. Tadauchi, ELKU); 1 female, Lake Chuzenji, Nikko, 11. v. 1976 (O. Tadauchi, ELKU). Ibaraki Pref.: 1 female and 2 males, Mt. Yamizo, 30. vi., 31. x. 1978 (H. Ishii, SCMH); 1 female, Mt. Yamizo, Daigo, 26. iv. 1978 (H. Ishii, SCMH). Tokyo Pref.: 1 male, Mt. Mitake, 3. x. 1953 (H. Nagase, ELKU). Yamanashi Pref.: 1 female, Masutomi, 20. ix. 1975 (J. Emoto, ELKU). Nagano Pref.: 1 female, Mt. Ontake, Otai, 14. v. 1976 (O. Tadauchi, ELKU). Fukui Pref.: 1 female, Kamikoike, Ono-shi, 14. v. 2002 (K. Mitai); 1 female, Kamiuchiha, Ono-shi, 28. viii. 2004 (T. Sugimoto); 1 female, Mt. Akausagi-yama, Ono-shi, 25. ix. 2002 (K. Mitai); 1 female, Noziri, Izumi-mura, 14. v. 2004 (T. Sugimoto). Ishikawa Pref.: 1 female, Mt. Hakusan, 29-31. viii. 1960 (T. Hidaka, ELKU); 7 females, Osugitani-rindo, Shiramine-mura, 3. v. 2003 (K.
Mitai). Gifu Pref.: 137 females, Mt. Norikura, Hatahoko, 8. v. 1976 (O. Tadauchi, ELKU); 1 female, Makido, Shoukawa-mura, 15. v. 2004 (T. Sugimoto); 2 females, Mihoro, Shirakawa-mura, 15. v. 2004 (T. Sugimoto). [JAPAN: KYUSHU] Fukuoka Pref.: 2 females, Mt. Hikosan, 9. v., 6. ix. 1951 (A. Habu \& Y. Hirashima, ELKU). Kumamoto Pref.: Gokanosho, 12. ix. 1971 (K. Kanmiya, ELKU). Miyazaki Pref.: 1 female, Mt. Kirishima, 1. v. 1958 (Y. Hirashima, ELKU); 2 males, Okawachi, 6. x. 1950 (Y. Hirashima, ELKU); 9 females, Mt. Sobo, Gokasho, Takachiho, 27. iv. 2003 (O. Tadauchi \& R. Murao).

Type depository. The holotype is deposited in the Entomological Laboratory, Faculty of Agriculture, Kyushu University (Fukuoka, Japan). The paratypes are deposited in the late Dr. S. F. Sakagami's Collection (21 females and 12 males) and Ebmer's Collection (4 females and 5 males). 


\section{Taxonomic positions}

The new species Lasioglossum caliginosum is placed into the L. fulvicorne-fratellum species-group, as defined by Ebmer (1995) in the L. carinate-Evylaeus super-species-group, on the basis of the following morphological characters. Female and male: body dusky colored. Female: mesoscutum and mesoscutellum with dense PP; IS reticulate. Male: gonostylus horizontal-flat; well-developed retrorse lobe. The propodeal dorsum of females in this species-group slightly longer than that of females of the closely related $L$. laticeps species-group. However, it is difficult to classify a species to the L. fulvicornefratellum or L. laticeps species-group with certainty based only on females.

Lasioglossum miyabei and L. yamanei are placed into the L. atroglaucum species-group in the $L$. greenEvylaeus super-species-group on the basis of the following morphological characters. Female and male: body with weak green-blue metallic luster; mesepisternum with fine and scattered PP; length of propodeal dorsum as long as the mesoscutellum. This species-group was first mentioned in a short notice in Ebmer et al. (1994) and then defined in detail by Ebmer (2002). Species of the $L$. atroglaucum species-group are similar to those of the $L$. morio species-group, especially by having a rather incon- spicuous dark green color of the head and thorax, usually brown-colored terga, and clear, but fine, scattered PP on the mesepisternum. But they can be distingiushed from species of the latter group by the length of the propodeal dorsum. While the length of the propodeal dorsum is shorter than that of the mesoscutellum in the L. morio species-group, it is as long as or longer than the mesoscutellum in members of the L. atroglancum species-group. The features of $L$. miyabei suggest a taxonomic position at the border of the L. atroglaucum species-group. Although the propodeum is narrowed and lengthened, a fine ridge is absent at the end of the lateral parts of the propodeum. The sterna of the male are simple (Fig. 12. A), and the gonostylus is club-like (Fig. 9. C-D). Photographs of the propodeum of members of the atroglaucum speciesgroup were published by Ebmer (2002, Female: Abb. 130, 133, 148, 151, 164, 167, 170, 173, 176, 181, 190, 197, 200. Male: Abb. 119, 1124, 137, 143, 161, 184). The two new species, L. miyabei and L. yamanei appear to have the same habitats as $L$. problematicum and $L$. virideglaucum of the L. atroglaucum species-gorup. Females of $L$. problematicum and L. virideglaucum are extremely similar and cannot be distinguished on an individual basis (Ebmer, 2002). In the male, both species can easily be distinguished by the distal parts of metasomal sterna as $L$. miyabei and L. yamanei (Fig. 12. A-D).

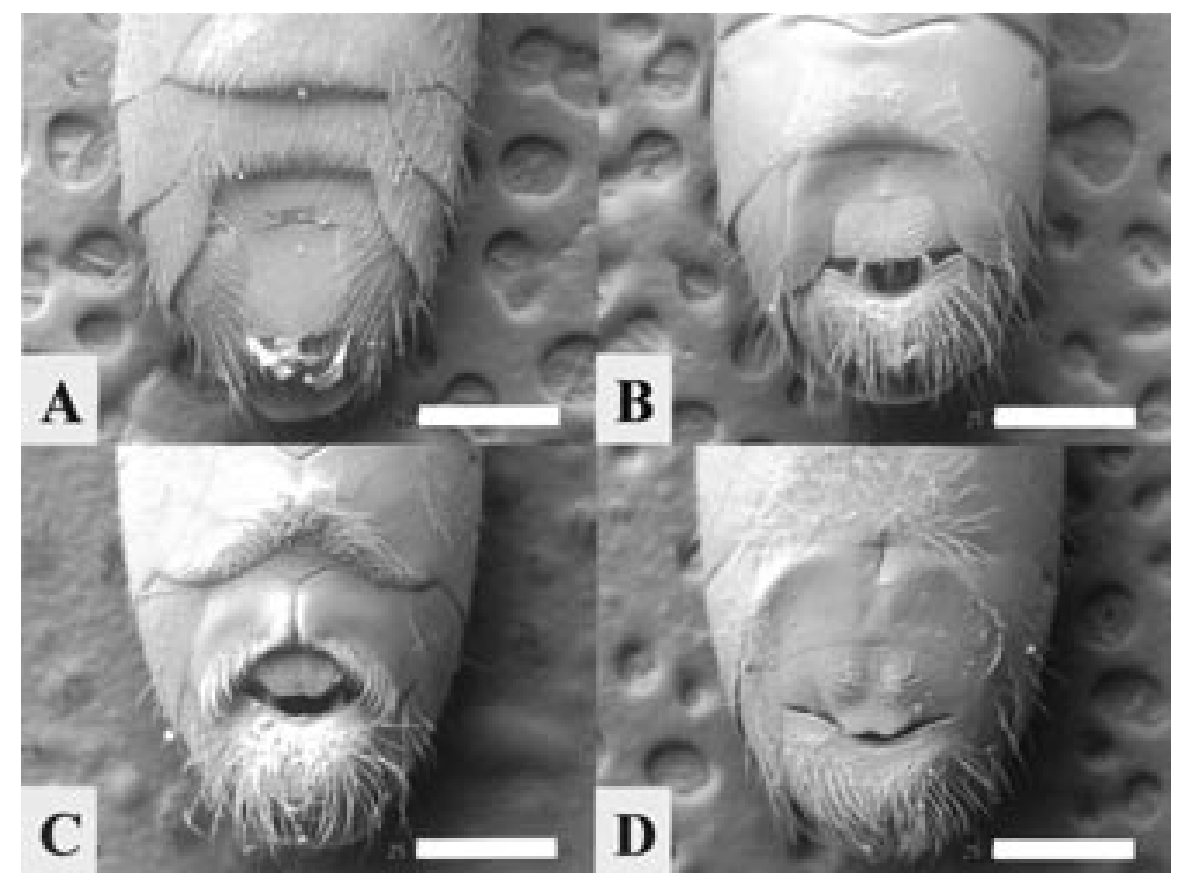

Fig. 12. A-D. Distal parts of male metasomal sterna. A: Lasioglossum (Evylaeus) miyabei sp. n., paratype. B: Lasioglossum (Evylaeus) yamanei sp. n., paratype. C: Lasioglossum (Evylaeus) problematicum (Blüthgen). D: Lasioglossum (Evylaeus) virideglaucum Ebmer et Sakagami. Scale: $0.5 \mathrm{~mm}$. 

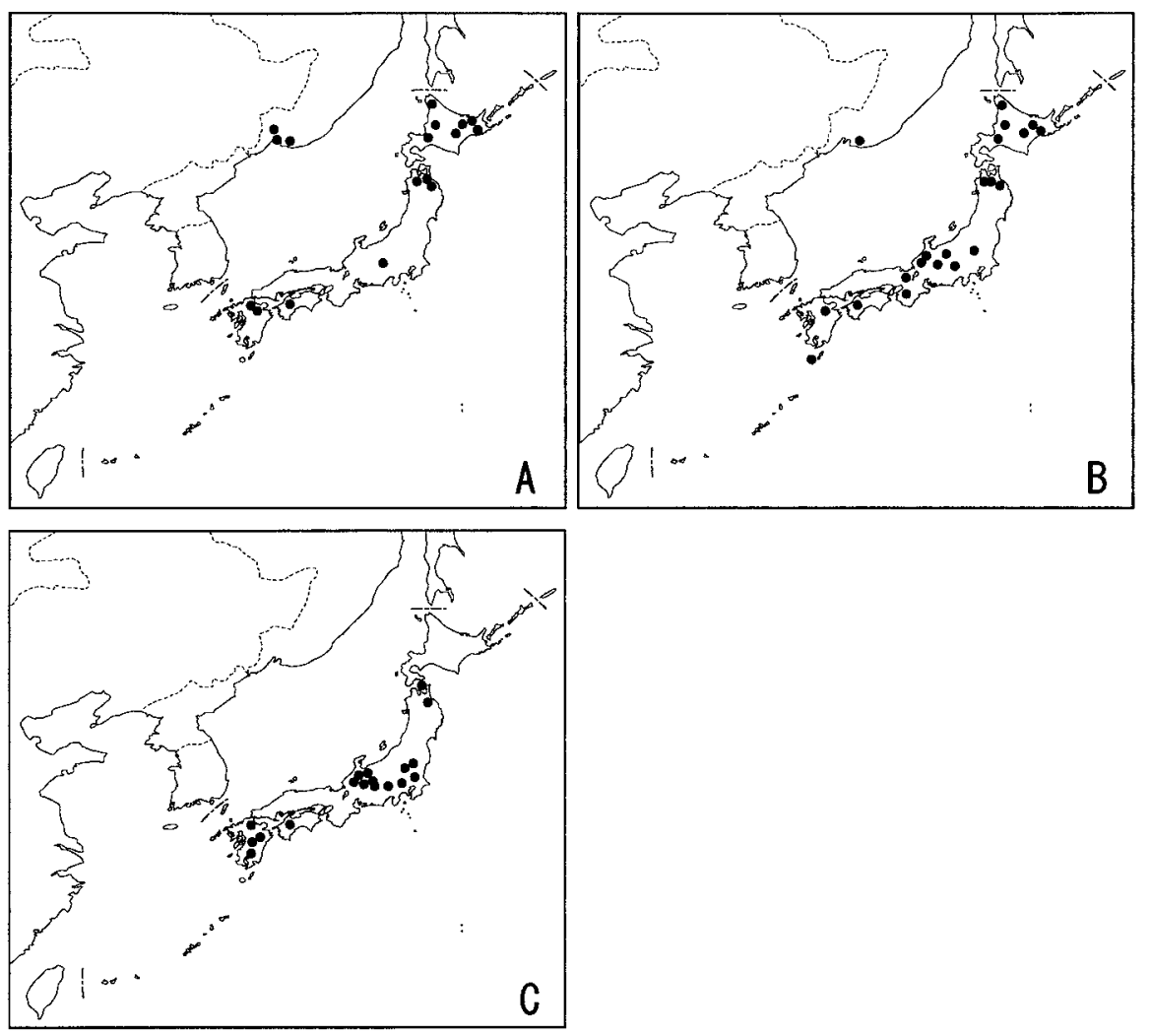

Fig. 13. A-C. Geographical distribution of three new species. A: Lasioglossum (Evylaeus) caliginosum sp. n. B: Lasioglossum (Evylaeus) miyabei sp. n. C: Lasioglossum (Evylaeus) yamanei sp. n.

\section{Acknowledgements}

We are especially indebted to the late Prof. Emeritus S. F. Sakagami (Hokkaido University) whose collection of Evylaeus was most useful in this study. One of us, Ebmer thanks to Mr. M. Quest (Münster University) for the English translations of diagnosis and the loan of specimens. We also acknowledge Dr. H. Fukuda (Sapporo), Dr. M. Goubara (Sendai) and Prof. S. Yamane (Ibaraki University) for their comments on the derivation of scientific name of L. miyabei and L. yamanei. This is a Contribution from the Entomological Laboratory, Faculty of Agriculture, Kyushu University, Fukuoka (Ser. 6, No. 24).

\section{References}

Ebmer, A. W., Y. Maeta \& S. F. Sakagami, 1994. Six new halictine bee species from southwest archipelago, Japan (Hymenoptera, Halictidae). Bull. Fac. Agr., Shimane Univ., 28: 23-36.

Ebmer, A. W., 1995. Asiatische Halictidae, 3. Die Artengruppe der Lasioglossum carinate-Evylaeus (Insecta: Hymenoptera: Apoidea: Halictidae: Halictinae). Linzer Biol. Beitr., 27:
$525-652$.

Ebmer, A. W., 2002. Asiatische Halictidae, 10. Neue Halictidae aus China sowie diagnostische Neubeschreibungen der von Fan \& Ebmer 1992 beschriebenen Lasioglossum-Arten (Insecta: Hymenoptera: Apoidea: Halictidae: Halictinae). Linzer Biol. Beitr., 34: 819-934.

Eickwort, G. C., 1969. A comparative morphological study and generic revision of the Augochlorine bees (Hymenoptera: Halictidae). Univ. Kansas Sci. Bull., 48: 325-524.

Goubara, M., Y. Sugimoto, R. Miyanaga \& Y. Maeta, 2002. Some notes on the distributional records of sweat bees in Japan (Hymenoptera, Halictidae). Chugoku Kontyu, 15: 31-37. (In Japanese.)

McGinley, R. J., 1986. Studies of Halictinae (Apoidea: Halictidae), I: Revision of new world Lasioglossum Curtis. Smiths. Contr. Zool., 429: 1-294.

Michener, C. D., 2000. The Bees of the World. The John Hopkins University Press, Baltimore \& London.

Sakagami, S. F., 1979. Systematic Studies of Social Bees. A Report of a Grant-in-Aid for Scientific Research (B) from the Ministry of Education, Japan (No. 348021). 27pp. (In Japanese.)

Sakagami, S. F. \& O. Tadauchi, 1995. Taxonomic studies on the halictine bees of Lasioglossum (Evylaeus) lucidulum subgroup in Japan with comparative notes on some Palaearctic species (Hymenoptera, Apoidea). Esakia, (35): 141-176. 